\title{
A meta-analysis of the inhibin network reveals prognostic value in multiple solid tumors
}

Eduardo Listik ${ }^{1 \dagger}$, Ben Horst ${ }^{1,2 \dagger}$, Alex Seok Choi $^{1}$, Nam. Y. Lee ${ }^{3}$, Balázs Győrffy ${ }^{4}$ and Karthikeyan Mythreye $^{1}$

Affiliations:

${ }^{1}$ Department of Pathology, University of Alabama at Birmingham, Birmingham AL, USA, 35294.

${ }^{2}$ Department of Chemistry and Biochemistry, University of South Carolina, Columbia SC, USA, 29208.

${ }^{3}$ Division of Pharmacology, Chemistry and Biochemistry, College of Medicine, University of Arizona, Tucson, AZ, 85721, USA.

${ }^{4}$ TTK Cancer Biomarker Research Group, Institute of Enzymology, and Semmelweis University Department of Bioinformatics and 2nd Department of Pediatrics, Budapest, Hungary.

\section{Corresponding author:}

Karthikeyan Mythreye, Ph.D.

Division of Molecular and Cellular Pathology, Department of Pathology, The University of Alabama at Birmingham.

WTI 320B, 1824 Sixth Avenue South, Birmingham, AL, USA, 35294.

Phone : +1 205.934.2746

E-mail : mythreye@uab.edu

${ }^{\dagger}$ The authors contributed equally to this work. 


\begin{abstract}
Inhibins and activins are dimeric ligands belonging to the TGF $\beta$ superfamily with emergent roles in cancer. Inhibins contain an $\alpha$-subunit $(I N H A)$ and a $\beta$-subunit (either INHBA or INHBB), while activins are mainly homodimers of either $\beta_{\mathrm{A}}(I N H B A)$ or $\beta_{\mathrm{B}}(I N H B B)$ subunits. Inhibins are biomarkers in a subset of cancers and utilize the coreceptors betaglycan (TGFBR3) and endoglin $(E N G)$ for physiological or pathological outcomes. Given the array of prior reports on inhibin, activin and the coreceptors in cancer, this study aims to provide a comprehensive analysis, assessing their functional prognostic potential in cancer using a bioinformatics approach. We identify cancer cell lines and cancer types most dependent and impacted, which included p53 mutated breast and ovarian cancers and lung adenocarcinomas. Moreover, INHA itself was dependent on TGFBR3 and ENG in multiple cancer types. INHA, INHBA, TGFBR3, and ENG also predicted patients' response to anthracycline and taxane therapy in luminal A breast cancers. We also obtained a gene signature model that could accurately classify $96.7 \%$ of the cases based on outcomes. Lastly, we cross-compared gene correlations revealing INHA dependency to TGFBR3 or $E N G$ influencing different pathways themselves. These results suggest that inhibins are particularly important in a subset of cancers depending on the coreceptor TGFBR3 and ENG and are of substantial prognostic value, thereby warranting further investigation.
\end{abstract}

18

19 Keywords: inhibin, activin, endoglin, betaglycan, TGF $\beta$, cancer, prognosis, bioinformatics. 


\section{INTRODUCTION}

Inhibins and activins are dimeric polypeptides members of the TGF $\beta$ superfamily, discovered initially as regulators of the follicle-stimulating hormone (FSH) ${ }^{1-9}$ Activins are homodimers utilizing different isoforms of the monomeric $\beta_{\mathrm{A}}$ or $\beta_{\mathrm{B}}$ subunits located on different chromosomes. ${ }^{10-12}$ Inhibin is a heterodimer assembled with an $\alpha$ subunit (INHA) and a $\beta$ subunit (either $\beta_{\mathrm{A}}, I N H B A$, or $\beta_{\mathrm{B}}, I N H B B$ ). Thus the inhibin naming reflects the $\beta$ subunit in the heterodimer: inhibin $\mathrm{A}\left(\alpha / \beta_{\mathrm{A}}\right)$ and inhibin $\mathrm{B}\left(\alpha / \beta_{\mathrm{B}}\right)$, respectively (Fig. 1a) ${ }^{8,13-16}$

Activins, much like TGF $\beta$, signal largely through SMAD2/3. ${ }^{17,18}$ Initial receptor binding of activin occurs via type II serine-threonine kinase receptors (ActRII or ActRIIB), which recruit and phosphorylate type I serine-threonine kinase receptors (ActRIB/Alk4 or ActRIC/Alk7) leading to subsequent phosphorylation of SMAD2/3. ${ }^{8,17,19-22}$ In multiple tissues, activin signaling is antagonized by inhibin. ${ }^{23}$ Thus, the biological and pathological function of activin is directly impacted by the relative levels of the mature $\alpha$ subunit. Inhibins, however, have a much lower affinity for the type II receptors compared to activins themselves which can be greatly enhanced by the presence of the Type III TGF $\beta$ receptor, betaglycan (TGFBR3), which binds inhibins' $\alpha$ subunit with high affinity. $8,19,23,24$ Thus the most established mechanism of antagonism by inhibin, is via its ability to competitively recruit ActRII preventing activin induced downstream signaling in a betaglycan-dependent manner. ${ }^{8,19,23,24}$ This competition model does not allow for direct inhibin signaling. However, conflicting reports on the presence of a separate high affinity inhibin receptor, ${ }^{25,26}$ recently discovered interactions of the $\alpha$ subunit with the Type I receptor Alk $4,{ }^{24}$ and our recent findings on the requirement of the alternate Type III TGF $\beta$ receptor endoglin $(E N G / C D 105)$ for inhibin responsiveness in endothelial cell function ${ }^{27}$ suggest complex roles for inhibins themselves.

Betaglycan and endoglin, are both coreceptors of the TGF- $\beta$ superfamily with broad structural similarities, ${ }^{28-30}$ including glycosylation in the extracellular domain (ECD), a short cytoplasmic domain and common intracellular interacting partners. ${ }^{31-36}$ Sequence analysis of betaglycan and endoglin reveals the highest shared homology in the transmembrane (73\%) and cytoplasmic domains (61\%), with the most substantial difference being in the ECD sequence that impacts ligand binding. ${ }^{28-30,37-39}$ Both betaglycan and endoglin knockouts (KOs) are lethal during embryonic development due to heart and liver defects and defective vascular development, respectively, highlighting the shared physiological importance of these coreceptors. ${ }^{40-43}$ In contrast to the above described similarities, betaglycan is more widely expressed in epithelial cells, while endoglin is predominantly expressed in proliferating endothelial cells. ${ }^{44-46}$

In cancer, betaglycan and endoglin impact disease progression by regulating cell migration, invasion, proliferation, differentiation, and angiogenesis in multiple cancer models. ${ }^{34,47-52}$ Betaglycan acts as a tumor suppressor in many cancer types, as its expression is lost in several primary cancers. ${ }^{53-55}$ However, elevated levels of betaglycan have also been reported in colon, triple-negative breast cancers and lymphomas, and has a role in promoting bone metastasis in prostate cancer, ${ }^{56}$ indicating contextual roles for betaglycan in tumor progression. ${ }^{48,57,58}$ Endoglin is crucial to angiogenesis, and increased endoglin in tumor micro-vessel density is correlated with decreased survival in multiple cancers. ${ }^{50,59}$ Evidence in ovarian cancer ${ }^{60,61}$ also suggests that 
much like other TGF- $\beta$ members may have dichotomous, context-dependent effects. ${ }^{62-69}$ Inhibins are early tumor suppressors, as the $I N H A^{-/}$mice form spontaneous gonadal and granulosa cell tumors. ${ }^{62}$ However, elevated levels of inhibins in multiple cancers are widely reported. ${ }^{63-66,70,71}$ Active roles for inhibins in promoting late stage tumorigenesis, in part via effects on angiogenesis, have also been demonstrated in both prostate cancer ${ }^{72}$ and more recently in ovarian cancer. ${ }^{27}$

Inhibins have been widely used as a diagnostic marker for a subset of cancers ${ }^{70,71,73}$ and both betaglycan and endoglin have been evaluated as therapeutic strategies in cancer. TRC-105, a monoclonal antibody against endoglin, was tested in twenty-four clinical trials. ${ }^{74-97}$ Current data also suggest benefits of combining anti-endoglin along with checkpoint inhibitors. ${ }^{98}$ Similarly a peptide domain of betaglycan called p144 and soluble betaglycan have been tested in multiple cancer types as an anti-TGF- $\beta$ treatment strategy that decreases tumor growth, angiogenesis, metastasis, and augments immunotherapy. ${ }^{99-106}$

Although prior and emerging studies revealed the dichotomous functions of inhibin's impact on cancer depending on either betaglycan ${ }^{8,19,23,24}$ or endoglin, ${ }^{27}$ further characterization of the relationship between inhibins-betaglycan-endoglin is vital. This study seeks to provide such prescient information by evaluating the significance, impact, and predictive value of this specific network (INHA, INHBA, INHBB, TGFBR3, and $E N G$ ) by utilizing publicly available genomic and transcriptomic databases.

\section{MATERIAL AND METHODS}

\subsection{Public databases data mining}

Clinical data, gene expression alterations, and normalized expression data of RNA-seq were obtained from cBioPortal. ${ }^{107,108}$ All available studies were assessed for copy number alterations (CNA) and a subset of cancer for mRNA data (Breast Invasive Carcinoma, Glioblastoma, Lower-grade glioma, Cervical Squamous Cell Carcinoma, Stomach Adenocarcinoma, Head and Neck Squamous Cell Carcinoma, Kidney Renal Clear Cell and Renal Papillary Cell Carcinomas, Liver Hepatocellular Carcinoma, Lung Adenocarcinoma, Ovarian Serous Cystadenocarcinoma, Prostate Adenocarcinoma, Uterine Corpus Endometrial Carcinoma). The results shown here are partly based upon data generated by the TCGA Research Network: https://www.cancer.gov/tcga. Survival data was generated from either KM Plotter ${ }^{109}$ or cBioportal (i.e., brain cancers). KM Plotter data for breast, ovarian, lung, and gastric cancer the survival analysis was derived using available gene chip data sets. All others were derived using the RNASeq Pan-cancer data sets. The Affymetrix Probe IDs used in gene chip analysis in KM Plotter were: INHA (210141_s_at), INHBA (204926_at), INHBB (205258_at), TGFBR3 (204731_at), and ENG (201808_s_at). Brain cancer data was generated from TCGA Pan Cancer Atlas 2018 dataset for glioblastoma and low-grade glioma. Overall survival (OS) was assessed for all cancer types except ovarian cancer (progression-free survival, PFS) and breast cancer (relapse-free survival, RFS). Gene expression was split into high and low using the median expression. Log-rank statistics were used to calculate the p-value and Hazard ratio (HR).

\subsection{Analysis of gene predictiveness to pharmacological treatment}


Gene predictive information on treatment regiments was obtained from ROC Plotter (http://www.rocplot.org/). ${ }^{110}$ Gene expression for the analyzed genes was compared using the Mann-Whitney U test. Receiver Operating Characteristic (ROC) plots and significance was also computed. ROC curves were compared using Area Under the Curve (AUC) values, and values above 0.6 with a significant $\mathrm{p}$ value were considered acceptable. ${ }^{110}$ ROC plot assessment was performed in all pre-established categories in ROC Plotter (i.e., breast and ovarian cancers, and glioblastoma). In breast cancer, subtypes (i.e., luminal A, luminal B, triple-negative, HER2 ${ }^{+}$) were also analyzed separately. Genes of interest were analyzed for complete pathological response in different pharmacological treatments. All available treatment options were investigated including, taxane, anthracycline, platin and temozolomide. Outliers were set to be removed in this analysis and only genes with a false discovery rate (FDR) below 5\% were considered.

\subsection{Clustering strategies for genes signatures}

From the normalized expression data from RNA-seq studies, the Spearman's $\rho$ coefficient was obtained for INHA, TGFBR3, and $E N G$. These data were clustered through a Euclidean clustering algorithm using Perseus 1.6.5.0 (MaxQuant). Clusters containing high and low correlations sets were isolated and compared in a pair-wise fashion. The derived genes obtained were checked for protein interaction in BioGRID (thebiogrid.org), ${ }^{111}$ and later included in pathway analysis, as described in section 2.5. All plots were performed in GraphPad Prism 8.0.

\subsection{Gene signature modeling for prognostics}

Gene signature modeling was performed using binary probit regression for each set of cancer types related to INHA, TGFBR3, ENG (Supplementary Table 5), and their respective outcomes (i.e., positive, 1; or negative, 0 ). The regression was iterated for presenting only significant elements in the following model:

$$
\operatorname{Pr}\left(Y=1 \mid x_{1}, \ldots, x_{k}\right)=\Phi\left(\beta_{0}+\sum_{i=1}^{k} \beta_{i} x_{i}\right)
$$

in which $x_{i}$ are RNA-seq V2 RSEM expression data for each gene, $\beta_{i}$ are obtained coefficients from this regression, $\Phi$ is the cumulative normal distribution function. Probability values closer to 1 indicate a positive outcome, while values close to 0 , indicate a negative outcome. Postestimation of specificity and sensitivity was also implemented. All regression studies were performed in Stata/SE 16.0.

\subsection{Pathway assessment}

For pathway analysis, DAVID Bioinformatics Resources 6.8 was used to acquire compiled data from the KEGG Pathway Database. ${ }^{112}$ Genes for the analysis were annotated to map to human pathways. The significant outputs were then assessed for the percentage of genes from analyzed 
sets and their relevance. To compare pathways between two sets, a pathway significance value ratio $\left(-\log _{10} \mathrm{R}\right)$, in which $\mathrm{R}$ is the ratio, was analyzed. Only pathways with an FDR value below $5 \%$ were considered.

\subsection{Gene dependency Analysis}

Gene dependency of $I N H A, T G F B R 3, I N H B A, I N H B B$, and $E N G$ was analyzed using the DepMap portal (www.depmap.org). ${ }^{113}$ Gene expression through Expression Public20Q1 dataset was analyzed via comparing it with RNAi and CRISPR datasets. Perturbed genes with similar trend correlation values with two or more perturbation methods were compiled. Genes commonly affected by perturbation methods were plotted onto a Venn diagram.

\section{RESULTS}

\subsection{Inhibins and activins are altered in human cancer}

We and others reported previously diverse roles for members of the inhibin/activin family in cancer. $8,27,114-117$ Our and prior mechanistic studies in cancer indicate a strong dependency of inhibin function on betaglycan and endoglin. ${ }^{24,27,118-121}$ To begin to evaluate the impact of this relationship more broadly in cancers we analyzed gene alterations including mutations, amplifications, and deletions for the genes encoding inhibin/activin subunits INHA, INHBA, $I N H B B$, and the key coreceptors - TGFBR3, and $E N G$ (Fig.1a) in all public datasets available in cBioPortal (Fig.1b, Supplementary Table 1). Percentage of patients from the whole cohort that possessed any of the alterations either by themselves or concomitantly was analyzed. We find that melanoma (16.26\%), endometrial (13.16\%), esophagogastric $(10.85 \%)$, and lung (10.69\%) cancers revealed the highest alterations for the genes. The alterations for the genes varied, with $I N H B A$ and $T G F B R 3$ exhibiting higher rates of alterations ( $0-5.65 \%$ and $0.17-3.91 \%$ respectively) that also varied by cancer type. The range for $I N H A, I N H B B$, and $E N G$ was found to be between $0-2.38 \%, 0-2.62 \%$, and $0-3.23 \%$ respectively (Fig. $1 b$ ).

In comparing expression levels of each of the genes in the same TCGA datasets as in Fig. $1 \mathrm{~b}$, we find that overall $E N G$ is the most highly expressed gene (Fig. 1c) with variance among different cancer types (e.g., lower-grade glioma and cervical vs. renal clear cell and lung adenocarcinoma, $\mathrm{p}<0.0001$ ) and subtypes (e.g., luminal A vs. luminal B breast cancers, $\mathrm{p}<$ 0.0001). Interestingly, TGFBR3 expression differed most notably between glioblastoma and lower-grade gliomas $(\mathrm{p}<0.0001)$, and breast cancers exhibited higher expression as compared to ovarian and endometrial $(\mathrm{p}<0.0001)$. INHBB in contrast was mostly expressed in renal clear cell and hepatocellular carcinomas, which differs from renal papillary cell carcinoma and cervical cancer $(\mathrm{p}<0.0001)$. Both INHBA and INHA were the least expressed as compared to the others (Fig. 1c). Exceptions were head and neck and esophagogastric cancers that had high expression of $I N H B A$ and lung adenocarcinoma and renal clear cell carcinoma that had high expression of INHA.

While the above analysis examined patient tumors, we next examined cell lines as a way to delineate model systems for future studies. For these analyses, we used the DepMap project 
(www.depmap.org) $)^{113}$ which is a comprehensive library of human genes that have been either knocked down or knocked out through CRISPR technology in 1,776 human cell lines representing multiple cancer types. ${ }^{122-124}$ Dependency scores representing the probability of queried gene dependency for each cell line and thereby cancer type is obtained. ${ }^{125}$ Here, we find that the ligand encoding gene $I N H A$ displayed higher dependency than the activin subunit isoforms INHBA or $I N H B B$ or either receptors $T G F B R 3$ and $E N G$ (Fig. 1d). Notably, esophageal, gastric, and ovarian cancers had the highest dependency results for INHA $(\geq 14 \%)$ consistent with the alterations seen in Fig. 1c. Within these cancers, INHBA exhibited higher dependency values in ovarian cancer $(6 \%)$ albeit not as high as INHA. Besides $I N H B B$ in myeloma (6\%), no other notable dependency relationships was observed.

In an attempt to identify genes most impacted by alteration to each of the individual genes, we examined how RNAi and CRISPR interventions would affect their correlation to specific genes. Those similarly affected by these techniques were found to be dependent on the investigated set of genes. We find that $E N G$ exhibited the highest number of dependent genes (Fig. 1e, $\mathrm{n}=71$ ) followed by INHBA (57), INHBB (49), TGFBR3 (44) and INHA (30) (Fig. 1e, Supplementary Table 1). Interestingly, only a total of 5 genes were commonly dependent between $I N H A$ and the other genes (Fig. 1e, MAX with INHBA and GRPEL1, SF3B4, ESR1, and TFAP2C with INHBB). $I N H B A$ on the other hand had several common dependent genes most notably 13 genes were common with ENG dependency (e.g., VCL, TLN1, and LYPD3).

\subsection{Effect of inhibins and the coreceptors on patient survival varies by cancer type}

Since alterations in expression of inhibin, activin, TGFBR3 and $E N G$ exist in human cancers and prior studies have implicated each of these in patient outcomes; ${ }^{27,52,59,71,114,126-129}$ we conducted a comprehensive analysis of each of these genes on overall survival (OS), progressionfree survival (PFS), or relapse free survival (RFS) in a broad panel of cancers. The goal here was to identify the patients and cancer types most impacted by changes in gene expression. Analysis was conducted using datasets in KM Plotter ${ }^{109}$ (Fig. 2, 3 and summarized in Supplementary Table 2). We find that not all cancers are equally impacted. Of note, we find that in both breast and ovarian cancers all five genes were either positive predictors of survival or non-predictive except $I N H B B$ in breast $(\mathrm{HR}=1.06, \mathrm{p}=0.034)$ and $I N H B A$ in ovarian $(\mathrm{HR}=1.16, \mathrm{p}=0.047)$ (Fig. 2). However, in p53 mutated cancers, INHA was a strong negative predictor of survival for both breast and ovarian cancers $(\mathrm{HR}=1.99, \mathrm{p}=0.0056$ and $\mathrm{HR}=1.55, \mathrm{p}=0.0039$, respectively), along with $E N G$ in ovarian cancer $(\mathrm{HR}=1.36, \mathrm{p}=0.0098$, Fig. 2, 3). Additionally, in lung cancers, $I N H A$ and $E N G$ differed from TGFBR3, as INHA $(\mathrm{HR}=1.26, \mathrm{p}=0.00029)$ and $E N G(\mathrm{HR}=1.20, \mathrm{p}=0.0056)$ were both negative predictors of survival while $T G F B R 3(\mathrm{HR}=0.65, \mathrm{p}=3.4 \mathrm{E}-7)$ was a strong positive predictor of survival (Fig. 2). Specifically, we find that $I N H A$ and $E N G$ are robust predictors of poor survival in lung adenocarcinomas but not in squamous cell carcinomas (Fig. 2, 3). Gastric cancers represent another robust cancer type where all five genes were negatively correlated with survival (Fig. 2, 3). Since HER2 expression is a frequent abnormality in gastric cancer, ${ }^{130}$ we examined if there were any differences in survival associated with HER 2 expression. All five genes in both $H E R 2^{+}$and HER2- gastric cancers, except INHBA in HER2- gastric cancers, were negatively correlated with survival (Fig. 2). In kidney cancers, INHA was a negative predictor of survival in both renal clear cell and renal papillary cell carcinoma (Fig. 2, 3), consistent with 
222

223

224

225

226

227

228

229

230

231

232

233

234

235

236

237

238

239

240

241

242

243

244

245

246

247

248

249

250

251

252

253

254

255

256

257

258

259

260

261

262

263

prior findings. ${ }^{27}$ TGFBR3 was a strong positive predictor of survival in both renal clear cell carcinoma $(\mathrm{HR}=0.46, \mathrm{p}=2.1 \mathrm{E}-7)$ and renal papillary cell carcinoma $(\mathrm{HR}=0.53, \mathrm{p}=0.042$, Fig. $2,3) . E N G(\mathrm{HR}=0.51, \mathrm{p}=8.6 \mathrm{E}-6)$ was a positive predictor of survival in renal clear cell carcinoma but not significantly associated with survival in renal papillary cell carcinoma (Fig. 2). Finally, in brain cancers, INHA was a negative predictor of survival in glioblastoma but a positive predictor in low-grade gliomas (Fig. 2). Of note, $E N G$ appeared to have a lower range of HR values compared to INHA and TGFBR3. INHBA and $I N B B B$ were not as significantly correlated with survival as $I N H A, E N G$, and TGFBR3. INHBA was significantly correlated with 8 cancer types while $I N H B B$ was significantly correlated with 9. INHBA and $I N H B B$ showed similar correlations with survival in gastric cancers, specifically $\mathrm{HER}^{+}$, and renal papillary cell carcinoma (Fig. 2). $I N H B A$ and $I N H B B$ showed opposing effects however in liver cancer where $I N H B A(\mathrm{HR}=0.62$, $\mathrm{p}=0.0086)$ was a strong positive predictor but $I N H B B(\mathrm{HR}=1.52, \mathrm{p}=0.025)$ was a potent negative predictor (Fig. 2).

Since inhibin's biological functions have been shown to be dependent on the coreceptors TGFBR3 and $E N G,{ }^{24,27,118-121}$ we examined the impact of INHA based on the expression levels of each of the co-receptor (Table 1). In this analysis, we find that that when separating patients into high or low expressing TGFBR3 or ENG groups (Table 2) in p53 mutated breast cancers, where $I N H A$ is a negative predictor of survival in all patients (Fig. 2), INHA was only a predictor of poor survival in patients with low TGFBR3 $(\mathrm{HR}=2.29, \mathrm{p}=0.015)$ or low $E N G(\mathrm{HR}=2.24, \mathrm{p}=0.035)$. Interestingly, this trend was also repeated in renal clear cell carcinoma, where INHA was only a predictor of survival in $T G F B R 3$ low $(\mathrm{HR}=2.75, \mathrm{p}=9.0 \mathrm{E}-06)$ and $E N G$ low $(\mathrm{HR}=2.6, \mathrm{p}=2.5 \mathrm{E}-$ 06, Table 1). In contrast to breast and renal clear cell cancers where TGFBR3 and ENG both impacted the effect of INHA on survival, TGFBR3 levels did not change INHA's impact on p53 mutated serous ovarian cancers (Table 1). In $E N G$ high p53 mutated serous ovarian cancer patients, $I N H A$ had a more significant negative prediction outcome $(\mathrm{HR}=2.12, \mathrm{p}=1.8 \mathrm{E}-6)$ compared to $E N G$ low $(\mathrm{HR}=0.8, \mathrm{p}=0.18$, Table 1$)$. Similar outcomes were observed in lung adenocarcinomas with respect to $T G F B R 3$, where $I N H A$ remained a strong negative predictor of survival in patients regardless of TGFBR3 expression levels (Table 1). However, INHA remained a robust negative predictor of survival in lung adenocarcinomas patients expressing low $E N G(\mathrm{HR}=2.12, \mathrm{p}=$ $0.00041)$ but was not significant in $E N G$ high expressing patients $(\mathrm{HR}=1.25, \mathrm{p}=0.14)($ Table 1$)$.

Together, these findings suggest that $I N H A$ expression as a predictive tool for survival is influenced by the coreceptors $E N G$ and $T G F B R 3$ in renal clear cell, lung, and p53 mutated breast and ovarian cancers. INHA is dependent on these coreceptors in all breast and ovarian cancers.

\subsection{Inhibins and activins can predict response to chemotherapy in luminal A breast cancer}

We next evaluated the pathological response based classification for each of the genes using the receiver operating characteristic (ROC) plotter (www.rocplot.org) to validate and rank $I N H A, I N H B A / B, T G F B R 3$ and $E N G$ as predictive biomarker candidates. ${ }^{110}$ In a ROC analysis, an area under the curve (AUC) value of 1 is a perfect biomarker and an AUC of 0.5 corresponds to no correlation at all. We first entered all genes to allow for FDR calculation for each gene at FDR cutoff of 5\% (Supplementary Table 3). We next examined individual genes and find that in luminal A breast cancers $E N G, T G F B R 3, I N H A$, and $I N H B A$, were better performing as compared to 
$I N H B B$ particularly for taxane or anthracycline based chemotherapy regimens. ROC plots for the two regimens are displayed in Fig. 4 and Supplementary Table 3.

Both $E N G$ and $T G F B R 3$ were predictive in other cancer types as well (Supplementary Table 3). Specifically, while $E N G$ performed better in taxane treatments in $H E R 2^{+}$breast cancer subtype, TGFBR3 performed better for taxane regimens in triple-negative breast cancer (TNBC) and serous ovarian cancer. Interestingly, examining expression (Fig. $4 \mathrm{~b}$ ) revealed that in the same luminal A breast cancers INHA, ENG and INHBA are less expressed in responders to pharmacological treatment while TGFBR3 is more expressed in these responder groups (Fig. 4b). Similar trends for TGFBFR3 expression were seen in TNBC and serous ovarian cancer groups where $T G F B R 3$ was more expressed in the responders' group for taxane regimens. ENG was also more expressed in $H E R 2^{+}$breast cancer patients who respond to taxane therapy, which was opposite to the luminal A subtype expression levels (Fig. 4b). Full data for the ROC curve assessment is available in Supplementary Table 3. In summary INHA, INHBA, TGFBR3, and ENG display clear discrepant profiles of expression among responders and non-responders to both anthracycline and taxane chemotherapy for distinct breast cancer subtypes, specifically luminal A, and serous ovarian cancer. These genes also harbor a possible predictive value to indicate responsiveness to these therapy regimens. Moreover, ENG expression could also differentiate luminal A and $H E R 2^{+}$breast cancers response to taxane therapy. INHBB on the other hand had no predictive value in the assessed cancer types.

\subsection{Gene signatures from inhibins can predict patient survival outcomes}

Given that $I N H A, T G F B R 3$, and $E N G$ impact patient outcomes more broadly and more significantly that $I N H B B$ and $I N H B A$, and the prior direct functional dependency of TGFBR3 and $E N G$ to inhibin function rather than $\operatorname{activin}^{38,131}$ we examined signatures associated with either a negative or positive outcome for each of the three genes. Cancer types that presented different survival predictions for INHA, TGFBR3, or ENG were assessed (Fig. 5a), and cancer types in which each gene would have a similar patient outcome (i.e., positive overall survival outcome $v s$. negative overall survival outcome) were separated into groups (e.g., INHA positive outcome vs. negative outcome, Fig. 5a).

Spearman's $\rho$ coefficient was calculated for all RNA-seq gene data provided in each of these datasets, and values were clustered, and genes that were either positively and negatively correlated with each individual INHA, TGFBR3 or ENG genes were identified (Supplementary Table 4). The top correlated genes from the positive outcome set were then pairwise compared to genes that had lower correlations in the negative outcome set, and vice-versa to obtain a subset of common genes. ${ }^{132-135}$ Examples include TGFB2 and HOXA1 where genes correlated to INHA in the negative outcome set, and $O G G 1$ and $S T A P 2$ in the positive outcome group. For TGFBR3, APIM1 and RILPL1 correlated in the negative outcome context, while FZD5 and MYCN in the positive one. No gene signatures were obtained for $E N G$. As indicated in section 3.2, the HR value range was the smallest for $E N G$ in the assessed cancer types, which limits the differential gene signature analysis. All these genes also had their mRNA expression assessed in the respective cancer sets, contrasted, and evaluated for difference in expression (Fig. 5b). Except for 22 genes 
from sets in which INHA or TGFBR3 had distinct predictions of survival (e.g., CHSY1, LDLR, $P P A R G, M I A 2, T O X 3$ ) all others exhibited significant alterations in gene expression (Fig. 5b).

The altered genes from Fig. $5 \mathrm{~b}$ whose difference in expression was significant, were assessed for protein interactions and these iterated for pathway analysis using BioGRID (thebiogrid.org, Fig. 5c). ${ }^{111}$ We find that INHA gene sets were associated with either PD-L1 expression and PD-1 checkpoint, Rap1 signaling pathways in patients with positive outcomes or cell cycle regulation in patients with negative outcomes. TGFBR3 associated genes on the other hand, relied on VEGF and $M A P K$ signaling pathways for patients with positive outcome and $I L$ $17, p 53$, or even Wnt signaling pathways in the negative outcome scenario. Detailed descriptions of analyzed genes and pathways are compiled in Supplementary Table 4.

To determine if the genes associated with INHA and TGFBR 3 had true prognostic value, a Probit regression model was applied to the normalized mRNA expression of the genes in Supplementary Table 5. The regressions were analyzed for the cancers from Fig. 2a and Fig. 2d which had clear outcomes for either INHA, or TGBFR3. The final coefficients and entry genes are also provided in Supplementary Table 5. We find that the INHA model had 43 genes as dependent elements, and the TGFBR 3 model had 37 genes. However, the most suitable model obtained from these sets is the TGFBR3 model, which has a high goodness of fit $\mathrm{p}$-value $(\mathrm{p}=0.9494)$, sensitivity (98.42\%), specificity (91.56\%), and accuracy $(96.70 \%$, Table 2$)$.

These analyses reveal that a differential signature obtained from INHA, along with one of its main binding receptors (i.e., $T G B F R 3$ ) are able to faithfully predict a patient's outcomes in a wide spectrum of cancer types (e.g., kidney, lung, head and neck, breast, liver, ovarian, stomach, endometrial).

\subsection{Functional analysis and interpretation of inhibin's mechanism of action}

Prior functional studies indicate a dependency on $E N G$ and TGFBR3 for inhibin responsiveness. ${ }^{38,131}$ To test if these biological observations hold in patient datasets, we performed supervised clustering using Euclidean algorithm of genes correlating with either INHA, ENG or $T G F B R 3$ using the RNA-seq data for cancer types with the most significant impact as determined in Fig. 6a. Only the most enriched transcripts that were either positively or negatively correlated transcripts are shown in Fig. 6a. Most enriched genes from these clusters were then compared amongst each other in all pairwise combinations for similarities (e.g., positively correlated to INHA $v s$. negatively correlated to $T G F B R 3$, and so on, Fig. 6b).

We find that INHA and TGFBR3 comparison rendered 1,430 genes, in which $24.6 \%$ were exclusive to INHA (e.g., DLL3, GPC2, TAZ, TERT, XYLT2) 37.7\% to TGFBR3 (e.g., CCL2, CCR4, EGFR, GLCE, IL1ORA, IL7R, ITGA1, ITGA2, JAK1, JAK2, SRGN, SULF1, TGFBR2), and 13.1\% were positively correlated to both (e.g., CSPG4, COL4A3, FGF18, NOTCH4, SMAD9). When $I N H A$ was assessed with respect to $E N G$ we find 1,773 genes of which, $11.2 \%$ were exclusive to INHA (e.g., GDF9, PVT1), 21.3\% to ENG (e.g., CCL2, GPC6, IL10, IL10RA, IL7R, INHBA, ITGA1, ITGB2, JAK1, SRGN, SULF1, TGFB1, TGFBR2) and $10.0 \%$ were highly correlated to both (e.g., CSPG4, DLL1, FGF18, FZD2, NOTCH4). Lastly, the comparison between $E N G$ and 
TGFBR3 returned 1,938 genes. However, very few were exclusive to either TGFBR3 (2.84\%) or $E N G(0.16 \%)$, revealing a high functional resemblance between both of these receptors, as most of the profiled genes correlated to both of them (48.5\%, e.g., ADAM9, -23, ADAMTS1, -2, -5, -8, -9, CCL2, CSF1R, DLL4, ESR1, FGF1, FGF2, FGF18, GLI1, -2, -3, GPC6, IL10RA, ITGA1, ITGA5, JAK1, MMP2, SDC3, SRGN, SULF1, TGFB3, TGFBR2, TNC, TWIST2, XYLT1, ZEB1) or none of them.

We next used each gene set from the cross-comparisons in Fig. 6b to identify pathways using KEGG. ${ }^{136}$ Unique pathways with an FDR below 5\% were identified for the comparisons and are presented in Fig. 6c. Although several common pathways were present between groups, such as PI3K-Akt and Ras signaling pathways (see Supplementary Table 6), some unique pathways were present as well. $E N G$, for instance, was more exclusively related to cytokine-cytokine receptor interaction and natural killer mediated cytotoxicity (Fig. 6c), while TGFBR3 was more exclusively related to proteoglycans interaction and chemokine signaling. While cell cycle and DNA replication were not directly associated with $E N G$ and $T G F B R 3$, Rap1 signaling and Extracellular matrix (ECM)-receptor interactions were both impacted by ENG and TGFBR3 (Fig. 6c). However, no independent pathway could be pinpointed to $I N H A$ alone, revealing dependency on either TGFBR3 or ENG. These studies indicate that inhibin's effects may vary depending on whether $E N G$ is more highly expressed as compared to TGFBR3 with significant relevance to defining mechanism and impact of changes in components of this pathway.

\section{DISCUSSION}

This study aimed to evaluate comprehensively the influence of the inhibin-activin network in cancer. Our findings provide significant new information on the specific cancers impacted by the genes investigated here, INHA, INHBA, INHBB, ENG and TGFFBR3, and shed light on potential functional dependencies. Additional gene signature analysis reveals that INHA, along with one of its main receptors (i.e., TGBFR3) faithfully predicts patient outcomes in a wide spectrum of cancer types.

TGF $\beta 1$ is a representative member of the TGF $\beta$ family that has been significantly investigated previously. ${ }^{137}$ However, less information exists about the precise impact and role of other members like inhibins and activins. Our findings that INHA is significantly associated with survival in sixteen of the twenty-one cancers analyzed, correlating positively with survival in six cancers and negatively in ten (Fig. 2), highlight INHA's differential role as a tumor suppressor or promoter depending on the specific cancer type. In highly angiogenic tumors like renal clear cell carcinoma ${ }^{138}$ and glioblastoma, ${ }^{139}$ we found $I N H A$ expression to be a significant negative predictor of survival. INHA's role in promoting tumorigenesis in these cancer types may occur through its effects on angiogenesis as has been previously reported for a subset of ovarian and prostate cancer $^{27,} 72$ warranting further investigation. In Luminal A breast cancers, we observed that increased INHA expression was associated with unresponsiveness to chemotherapy (Fig. 4) while in survival data it was a positive predictor of survival (Fig. 2). This apparent contradiction can perhaps be explained by the fact that data in KM Plotter contains information on patients that have undergone a wide array of treatments. Likely, $I N H A$ is predictive of response to some treatments but not others. Curiously, in both breast and ovarian cancers, INHA was only a negative predictor 
of survival in patients that had p53 mutations indicating a potential dependency of INHA functions on the p53 status. INHA expression alterations have been observed in p53 mutated adrenocortical tumors and INHA was suggested to be a contributing factor to tumorigenesis in these cancers. ${ }^{140}$ One of the most characterized transcriptional activators of INHA is GATA4, ${ }^{141}$ which can also regulate $\mathrm{p} 53$ in cancer and could be responsible for the different survival outcomes we see for INHA in p53 mutated cancers versus wild-type p53 cancers. ${ }^{142,143}$ INHA expression changes and the link to functional outcomes in the background on p53 mutations remains to be fully elucidated.

Between the TGF- $\beta$ family co-receptors ( $E N G$ and TGFBR3) implicated in cancer progression and inhibin function, $E N G$ was more expressed (Fig. 1c), particularly in lung adenocarcinoma and gastric cancers, corresponding with $E N G$ being a strong negative predictor of survival (Fig. 1c, 2). These findings are consistent with prior experimental findings as well. ${ }^{144,145}$ In p53 mutated cancers, ENG remained a negative predictor. ROC Plotter analysis revealed decreased $E N G$ expression to be associated with response to anthracycline therapy in Luminal A breast cancer patients (Fig. 4). However, a previous study showed that positive ENG expression was associated with increased survival in breast cancer patients who had undergone anthracycline treatment. ${ }^{146}$ While Isacke and colleagues did not report a specific subtype in their analyzed cohort, ${ }^{146}$ we obtained significant results for Luminal A breast cancer, specifically. Moreover, an additional study performed in acute myeloid leukemia showed an inverse relationship to that of Isacke et al., consistent with our results in Luminal A breast cancer. ${ }^{146,147} \mathrm{We}$ also found $E N G$ to be a predictive of response to taxane therapy regimens. An inverse relationship between $E N G$ expression was observed in responders for Luminal A and $\mathrm{HER}^{+}$breast cancer, with responders expressing high $E N G$ in $H E R 2^{+}$breast cancers but low levels of $E N G$ in Luminal A cancers (Fig. 4). As Luminal A breast cancer is $H E R 2^{-}, E N G$ could be affected by HER2 status in these cancer types. In our analysis, expression data was only obtained for Luminal A breast cancers not $H E R 2^{+}$ so differences in expression between the two were not analyzed.

Consistent with TGFBR3's role as a tumor suppressor in many cancers, we found it to be a significant positive predictor of survival in all but two cancers (i.e., endometrial and all gastric subtypes, Fig. 2). Increased TGFBR3 was predictive of response in all treatments and cancers we examined (Fig.4), further bolstering TGFBR3's role as a negative regulator of tumor progression. Specifically, Bhola et al. $(2013)^{148}$ showed increased levels of TGFBR3 in response to taxane in a small cohort $(\mathrm{n}=17)$ of breast cancer patients; however, response to therapy was not analyzed. TGFBR3 has been shown to act as a tumor suppressor in renal clear cell carcinoma ${ }^{126}$ and nonsmall cell lung cancers ${ }^{102}$ which was also confirmed here (Fig. 2). We were also able to expand $T G F B R 3$ 's role in renal cancer to papillary carcinomas as well (Fig. 2).

Expression of $E N G$ and TGFBR3 was not significantly different between wild-type and p53 mutated cancers indicating p53 likely does not impact expression itself. Whether protein secretion of these coreceptors is altered in these cancers is currently unknown, and cannot be ruled out, as previous studies have shown increased endoglin folding and maturation in p53 mutation settings. ${ }^{149}$ TGFBR3 also undergoes N-linked glycosylation, so a similar scenario to endoglin is possible. Alterations in protein maturation could explain the differential patient outcomes observed between wild-type and p53 mutated cancers, when assessing for $E N G$ and TGFBR3, despite changes in expression not being observed. 
INHA's dependency on each coreceptor examined in survival analysis revealed distinct signatures between different cancer types (Table 1). Prior studies indicate a requirement for $E N G$ in inhibin responsiveness and functions, ${ }^{27}$ which was borne out in patient survival data here (Table 1). However, a few outliers exist such as p53 mutated breast and renal clear cell carcinoma where $I N H A$ was not always dependent on increased $E N G$ and TGFBR3 expression. We found INHA to only be a negative predictor of survival in patients expressing low ENG indicating INHA might act independent of either coreceptor in these cancer types. The role of other receptors involved in mediating INHA's effects in these cancer types remains to be determined.

Gene signatures (Fig. 5) provided insights into how INHA, TGFBR3, or ENG would distinguish patients' outcomes. Some notable elements of this signature have been verified previously and even proposed as cancer biomarkers. For example, EPHA2 overexpression has been associated with decreased patient survival and promotes drug resistance, increased invasion, and epithelial to mesenchymal transition (EMT). ${ }^{150-153}$ HOXA1, a lncRNA overexpressed in cancers such as breast, melanoma, and oral carcinomas, drives metastasis and tamoxifen resistance. ${ }^{154-156}$ For TGFBR3 specifically, three genes revealed high discrimination between positive and negative outcomes: UGT1A9 and GLYATL1 were 25- and 35-fold more expressed in positive outcomes and $P 2 R X 3$ was 11.5-fold more expressed in negative outcomes. Of interest, UGT1A9 is a UDP-glucuronosyltransferase (UGT) whose activity has been implicated in drug resistance by affecting the bioactivity of the drug. ${ }^{157,158} \mathrm{We}$ speculate that as a proteoglycan, increased TGFBR3 could compete for UDP-glucuronate acid (GlcA) and UDP-xylose, both key elements for UGT1A9 activity, thereby potentially disrupting UGT associated resistance mechanisms and increasing the efficacy of chemotherapy. We also narrowed down which pathways differentiated patient outcomes for either INHA or TGFBR3. For positive outcomes, we found that INHA was associated with PD-L1, Ras, and Rap1 signaling pathways. In adverse outcomes, INHA was associated with Hippo, Wnt, and cell cycle pathways. Wnt has been shown to regulate $I N H A$ transcription in rat adrenal cortex and could increase $I N H A$ expression in certain tumors to promote tumorigenesis. ${ }^{159}$ Recent evidence indicates increased PD-L1 in dendritic cells in $\mathrm{INHA}^{-/-}$mice.${ }^{160} \mathrm{We}$ speculate that increased INHA in tumors may inhibit PD-L1 expression perhaps via antagonistic effect on other TGF- $\beta$ members, increasing anti-tumor immune responses.

There are currently no other cancer prognostic models based on our three assessed genes. The selected prognostic model showed high accuracy (96.7\%) with $98.42 \%$ sensitivity and $91.56 \%$ specificity (Table 2). Moreover, most prognostic cancer models are directed to either a specific cancer type (e.g., breast, prostate) or a cancer stage (e.g., lymph node metastases, phases). Our model includes at least ten tumor types, is in the top two for sensitivity, and among the second quartile of specificities on assessment of 48 prognostic cancer models. ${ }^{161-164}$ Thus, the INHATGFBR3-ENG signature has pan-cancer prognostic value.

Clustering analysis for genes correlated with $I N H A, T G F B R 3$, or $E N G$ in cancers (Fig. 6) revealed $E N G$ and $T G F B R 3$ had very few genes correlated exclusively to one or the other. As both receptors share similar structures and interact with common ligands, ${ }^{38}$ this is not unexpected. Similarly, since $E N G$ and $T G F B R 3$ had significant common gene associations this resulted in common pathways. For instance, a strong correlation with ECM-receptors and Rap1 signaling was observed. ENG has been shown to bind leukocyte integrins, promoting invasion, ${ }^{165}$ and ECM remodeling during fibrosis. ${ }^{166}$ TGFBR3 has been shown to regulate integrin localization and 
472 adhesion to ECM. ${ }^{167}$ ENG alone was associated with natural killer cell-mediated cytotoxicity 473 consistent with previous findings showing anti-endoglin therapy augmented immune response in 474 tumors by increasing NK cells, $\mathrm{CD} 4^{+}$, and $\mathrm{CD}^{+}$T lymphocytes. ${ }^{168}$

475 In conclusion, our pan-cancer analysis of the inhibin-activin network reveals a prognostic 476 signature capable of accurately predicting patient outcome. Gene signatures from our analysis 477 reveal robust relationships between INHA, ENG, and TGFBR3 and other established cancer 478 biomarkers. Survival analysis implicated members of the inhibin-activin network in cancers 479 previously unstudied as well as corroborated previous findings. Further analysis of the role of the 480 inhibin-activin network in cancer and relationship to other cancer associated genes, as well as 481 validation as predictive biomarkers to chemotherapy is needed.

\section{FUNDING}

484 This work was supported by the National Institutes of Health (NIH) Grant 5R01CA21945

485 to Mythreye Karthikeyan (KM) and by the 2018-2.1.17-TET-KR-00001, 2018-1.3.1-VKE-2018486 00032, and KH-129581 grants of the National Research, Development and Innovation Office, 487 Hungary to BG. 


\section{REFERENCES}

4951 Schwartz, N. B. \& Channing, C. P. Evidence for ovarian "inhibin": suppression of the secondary rise in serum follicle stimulating hormone levels in proestrous rats by injection of porcine follicular fluid. Proc Natl Acad Sci US A 74, 5721-5724,

4992 Keogh, E. J. et al. Selective suppression of FSH by testicular extracts. Endocrinology 98 , 500 997-1004, doi:10.1210/endo-98-4-997 (1976).

5013 De Jong, F. H. \& Sharpe, R. M. Evidence for inhibin-like activity in bovine follicular fluid. Nature 263, 71-72, doi:10.1038/263071a0 (1976). Setchell, B. P. \& Jacks, F. Inhibin-like activity in rete testis fluid. J Endocrinol 62, 675676, doi:10.1677/joe.0.0620675 (1974).

5 Woodruff, T. K., Lyon, R. J., Hansen, S. E., Rice, G. C. \& Mather, J. P. Inhibin and activin locally regulate rat ovarian folliculogenesis. Endocrinology 127, 3196-3205, doi:10.1210/endo-127-6-3196 (1990).

Cate, R. L. et al. Isolation of the bovine and human genes for Müllerian inhibiting substance and expression of the human gene in animal cells. Cell 45, 685-698, doi:10.1016/0092-8674(86)90783-x (1986).

5169 Ling, N. et al. A homodimer of the beta-subunits of inhibin A stimulates the secretion of Gaddy-Kurten, D. \& Vale, W. W. Activin increases phosphorylation and decreases stability of the transcription factor Pit-1 in MtTW15 somatotrope cells. J Biol Chem 270, 28733-28739, doi:10.1074/jbc.270.48.28733 (1995).

$52111 \quad$ W., V., A., H., C., R. \& J., Y. in Peptide Growth Factors and Their Receptors II Vol. 95 (Springer, Berlin, Heidelberg, 1990).

Makanji, Y. et al. Inhibin at 90: from discovery to clinical application, a historical review. Endocr Rev 35, 747-794, doi:10.1210/er.2014-1003 (2014). pituitary follicle stimulating hormone. Biochem Biophys Res Commun 138, 1129-1137, doi:10.1016/s0006-291x(86)80400-4 (1986).

Vale, W. et al. Purification and characterization of an FSH releasing protein from porcine ovarian follicular fluid. Nature 321, 776-779, doi:10.1038/321776a0 (1986).
Antenos, M., Zhu, J., Jetly, N. M. \& Woodruff, T. K. An activin/furin regulatory loop modulates the processing and secretion of inhibin alpha- and betaB-subunit dimers in pituitary gonadotrope cells. J Biol Chem 283, 33059-33068, doi:10.1074/jbc.M804190200 (2008).

13 Robertson, D. M. et al. Isolation of inhibin from bovine follicular fluid. Biochem Biophys Res Commun 126, 220-226, doi:10.1016/0006-291x(85)90594-7 (1985). 
52914 Rivier, J., Spiess, J., McClintock, R., Vaughan, J. \& Vale, W. Purification and partial $530 \quad$ characterization of inhibin from porcine follicular fluid. Biochem Biophys Res Commun 133, 120-127, doi:10.1016/0006-291x(85)91849-2 (1985).

53215 Ueno, N. et al. Isolation and partial characterization of follistatin: a single-chain $\mathrm{Mr}$ 35,000 monomeric protein that inhibits the release of follicle-stimulating hormone. Proc Natl Acad Sci U S A 84, 8282-8286, doi:10.1073/pnas.84.23.8282 (1987).

53516 Miyamoto, K. et al. Isolation of porcine follicular fluid inhibin of 32K daltons. Biochem Biophys Res Commun 129, 396-403, doi:10.1016/0006-291x(85)90164-0 (1985).

Attisano, L. \& Wrana, J. L. Signal transduction by the TGF-beta superfamily. Science 296, 1646-1647, doi:10.1126/science.1071809 (2002).

19 Gray, P. C. et al. Identification of a binding site on the type II activin receptor for activin and inhibin. J Biol Chem 275, 3206-3212, doi:10.1074/jbc.275.5.3206 (2000).

Attisano, L. et al. Identification of human activin and TGF beta type I receptors that form heteromeric kinase complexes with type II receptors. Cell 75, 671-680, doi:10.1016/0092-8674(93)90488-c (1993). receptor specificity by the type II receptors for TGF-beta or activin. Science 262, 900902, doi:10.1126/science.8235612 (1993). (1996).

Lewis, K. A. et al. Betaglycan binds inhibin and can mediate functional antagonism of activin signalling. Nature 404, 411-414, doi:10.1038/35006129 (2000). disrupt activin signaling. $J$ Biol Chem 287, 8060-8070, doi:10.1074/jbc.M111.293381 (2012). receptor system. Endocrinology 141, 2600-2607, doi:10.1210/endo.141.7.7540 (2000). to betaglycan, InhBP/p120 and the activin type II receptors. Mol Cell Endocrinol 196, 7993, doi:10.1016/s0303-7207(02)00227-7 (2002).

7 Singh, P. et al. Inhibin Is a Novel Paracrine Factor for Tumor Angiogenesis and Metastasis. Cancer Res 78, 2978-2989, doi:10.1158/0008-5472.CAN-17-2316 (2018). 
56428

565

566

567

568

569

570

571

572

573

574

575

576

577

578

579

580

581

582

583

584

585

586

587

588

589

590

591

592

593

594

595

596

597

598

López-Casillas, F. et al. Structure and expression of the membrane proteoglycan betaglycan, a component of the TGF-beta receptor system. Cell 67, 785-795, doi:10.1016/0092-8674(91)90073-8 (1991).

29 Wang, X. F. et al. Expression cloning and characterization of the TGF-beta type III receptor. Cell 67, 797-805, doi:10.1016/0092-8674(91)90074-9 (1991).

30 Gougos, A. \& Letarte, M. Primary structure of endoglin, an RGD-containing glycoprotein of human endothelial cells. J Biol Chem 265, 8361-8364 (1990).

31 Chen, W. et al. Beta-arrestin 2 mediates endocytosis of type III TGF-beta receptor and down-regulation of its signaling. Science 301, 1394-1397, doi:10.1126/science.1083195 (2003).

32 McLean, S., Bhattacharya, M. \& Di Guglielmo, G. M. $\beta$ arrestin2 interacts with T $\beta$ RII to regulate Smad-dependent and Smad-independent signal transduction. Cell Signal 25, 319-331, doi:10.1016/j.cellsig.2012.10.001 (2013).

33 Blobe, G. C., Liu, X., Fang, S. J., How, T. \& Lodish, H. F. A novel mechanism for regulating transforming growth factor beta (TGF-beta) signaling. Functional modulation of type III TGF-beta receptor expression through interaction with the PDZ domain protein, GIPC. J Biol Chem 276, 39608-39617, doi:10.1074/jbc.M106831200 (2001).

34 Mythreye, K. \& Blobe, G. C. The type III TGF-beta receptor regulates epithelial and cancer cell migration through beta-arrestin2-mediated activation of Cdc42. Proc Natl Acad Sci U S A 106, 8221-8226, doi:10.1073/pnas.0812879106 (2009).

35 Lee, N. Y., Ray, B., How, T. \& Blobe, G. C. Endoglin promotes transforming growth factor beta-mediated Smad 1/5/8 signaling and inhibits endothelial cell migration through its association with GIPC. J Biol Chem 283, 32527-32533, doi:10.1074/jbc.M803059200 (2008).

36 Lee, N. Y. \& Blobe, G. C. The interaction of endoglin with beta-arrestin2 regulates transforming growth factor-beta-mediated ERK activation and migration in endothelial cells. J Biol Chem 282, 21507-21517, doi:10.1074/jbc.M700176200 (2007).

37 Cheifetz, S. et al. Endoglin is a component of the transforming growth factor-beta receptor system in human endothelial cells. J Biol Chem 267, 19027-19030 (1992).

38 Kim, S. K., Henen, M. A. \& Hinck, A. P. Structural biology of betaglycan and endoglin, membrane-bound co-receptors of the TGF-beta family. Exp Biol Med (Maywood) 244, 1547-1558, doi:10.1177/1535370219881160 (2019).

39 Letamendía, A. et al. Role of endoglin in cellular responses to transforming growth factor-beta. A comparative study with betaglycan. J Biol Chem 273, 33011-33019, doi:10.1074/jbc.273.49.33011 (1998). 
40 Stenvers, K. L. et al. Heart and liver defects and reduced transforming growth factor beta2 sensitivity in transforming growth factor beta type III receptor-deficient embryos. Mol Cell Biol 23, 4371-4385, doi:10.1128/mcb.23.12.4371-4385.2003 (2003).

60241 Compton, L. A., Potash, D. A., Brown, C. B. \& Barnett, J. V. Coronary vessel development is dependent on the type III transforming growth factor beta receptor. Circ Res 101, 784-791, doi:10.1161/CIRCRESAHA.107.152082 (2007).

42 Li, D. Y. et al. Defective angiogenesis in mice lacking endoglin. Science 284, 1534-1537, doi:10.1126/science.284.5419.1534 (1999).

43 Arthur, H. M. et al. Endoglin, an ancillary TGFbeta receptor, is required for extraembryonic angiogenesis and plays a key role in heart development. Dev Biol 217, 42-53, doi:10.1006/dbio.1999.9534 (2000). cardiovascular system. Am J Physiol Heart Circ Physiol 299, H959-974, doi:10.1152/ajpheart.01251.2009 (2010).

Miller, D. W. et al. Elevated expression of endoglin, a component of the TGF-betareceptor complex, correlates with proliferation of tumor endothelial cells. Int J Cancer 81, 568-572, doi:10.1002/(sici)1097-0215(19990517)81:4<568::aid-ijc11>3.0.co;2-X (1999).

$61746 \quad$ Jenkins, L. M., Horst, B., Lancaster, C. L. \& Mythreye, K. Dually modified transmembrane proteoglycans in development and disease. Cytokine Growth Factor Rev 39, 124-136, doi:10.1016/j.cytogfr.2017.12.003 (2018).

Mythreye, K. \& Blobe, G. C. Proteoglycan signaling co-receptors: roles in cell adhesion, migration and invasion. Cell Signal 21, 1548-1558, doi:10.1016/j.cellsig.2009.05.001 (2009).

Gatza, C. E. et al. Type III TGF- $\beta$ receptor enhances colon cancer cell migration and anchorage-independent growth. Neoplasia 13, 758-770, doi:10.1593/neo.11528 (2011).

Burrows, F. J. et al. Up-regulation of endoglin on vascular endothelial cells in human solid tumors: implications for diagnosis and therapy. Clin Cancer Res 1, 1623-1634 (1995).

Paauwe, M. et al. Endoglin targeting inhibits tumor angiogenesis and metastatic spread in breast cancer. Oncogene 35, 4069-4079, doi:10.1038/onc.2015.509 (2016). invasive phenotype. Oncogene 27, 3567-3575, doi:10.1038/sj.onc.1211025 (2008).

63252 Paauwe, M. et al. Endoglin Expression on Cancer-Associated Fibroblasts Regulates 
63553 Hempel, N. et al. Loss of betaglycan expression in ovarian cancer: role in motility and 636 invasion. Cancer Res 67, 5231-5238, doi:10.1158/0008-5472.CAN-07-0035 (2007).

63754 Gordon, K. J., Dong, M., Chislock, E. M., Fields, T. A. \& Blobe, G. C. Loss of type III associated with epithelial to mesenchymal transition during pancreatic cancer

55 Turley, R. S. et al. The type III transforming growth factor-beta receptor as a novel tumor suppressor gene in prostate cancer. Cancer Res 67, 1090-1098, doi:10.1158/00085472.CAN-06-3117 (2007).

Cook, L. M. et al. Betaglycan drives the mesenchymal stromal cell osteogenic program and prostate cancer-induced osteogenesis. Oncogene 38, 6959-6969, doi:10.1038/s41388019-0913-4 (2019).

64757 Jovanović, B. et al. Transforming growth factor beta receptor type III is a tumor promoter in mesenchymal-stem like triple negative breast cancer. Breast Cancer Res 16, R69, doi:10.1186/bcr3684 (2014).

Woszczyk, D. et al. Expression of TGF betal genes and their receptor types I, II, and III in low- and high-grade malignancy non-Hodgkin's lymphomas. Med Sci Monit 10, CR3337 (2004).

Zhang, J., Zhang, L., Lin, Q., Ren, W. \& Xu, G. Prognostic value of endoglin-assessed microvessel density in cancer patients: a systematic review and meta-analysis. Oncotarget 9, 7660-7671, doi:10.18632/oncotarget.23546 (2018). for Metastasis to the Ovary. Cancers (Basel) 11, doi:10.3390/cancers11111710 (2019).

61 Zhang, J., Yuan, B., Zhang, H. \& Li, H. Human epithelial ovarian cancer cells expressing CD105, CD44 and CD106 surface markers exhibit increased invasive capacity and drug resistance. Oncol Lett 17, 5351-5360, doi:10.3892/ol.2019.10221 (2019). tumour-suppressor gene with gonadal specificity in mice. Nature 360, 313-319, doi:10.1038/360313a0 (1992). inhibin-like material in serum and gastric juice of patients with benign and malignant diseases of the stomach. Br J Cancer 51, 877-882, doi:10.1038/bjc.1985.133 (1985). tumor. Pancreas 36, e40-46, doi:10.1097/mpa.0b013e3181584643 (2008). 
67065 McCluggage, W. G., Maxwell, P., Patterson, A. \& Sloan, J. M. Immunohistochemical staining of hepatocellular carcinoma with monoclonal antibody against inhibin. Histopathology 30, 518-522 (1997). epithelial and granulosa cell tumours of the ovary. $J$ Pathol 181, 413-418, doi:10.1002/(SICI)1096-9896(199704)181:4<413::AID-PATH789>3.0.CO;2-U (1997).

Huang, J. J. \& Blobe, G. C. Dichotomous roles of TGF- $\beta$ in human cancer. Biochem Soc Trans 44, 1441-1454, doi:10.1042/BST20160065 (2016).

Ball, E. M., Mellor, S. L. \& Risbridger, G. P. Cancer progression: is inhibin alpha from Venus or Mars? Cytokine Growth Factor Rev 15, 291-296, doi:10.1016/j.cytogfr.2004.04.004 (2004). inhibin alpha subunit as a tumour suppressor in prostate cancer. Mol Cell Endocrinol 225, 73-76, doi:10.1016/j.mce.2004.02.015 (2004).

Robertson, D. M., Pruysers, E. \& Jobling, T. Inhibin as a diagnostic marker for ovarian cancer. Cancer Lett 249, 14-17, doi:10.1016/j.canlet.2006.12.017 (2007).

Walentowicz, P. et al. Serum inhibin A and inhibin B levels in epithelial ovarian cancer patients. PLoS One 9, e90575, doi:10.1371/journal.pone.0090575 (2014).

Balanathan, P. et al. Elevated level of inhibin-alpha subunit is pro-tumourigenic and prometastatic and associated with extracapsular spread in advanced prostate cancer. $\mathrm{Br} J$ Cancer 100, 1784-1793, doi:10.1038/sj.bjc.6605089 (2009).

69173 Mom, C. H. et al. Granulosa cell tumors of the ovary: the clinical value of serum inhibin A and B levels in a large single center cohort. Gynecol Oncol 105, 365-372, doi:10.1016/j.ygyno.2006.12.034 (2007).

(https://ClinicalTrials.gov/show/NCT01306058).

(https://ClinicalTrials.gov/show/NCT02560779). 
$70282 \quad$ (https://ClinicalTrials.gov/show/NCT02520063).

$70383 \quad$ (https://ClinicalTrials.gov/show/NCT03780010).

$70484 \quad$ (https://ClinicalTrials.gov/show/NCT01375569).

$70585 \quad$ (https://ClinicalTrials.gov/show/NCT01975519).

$706 \quad 86 \quad$ (https://ClinicalTrials.gov/show/NCT02396511).

$70787 \quad$ (https://ClinicalTrials.gov/show/NCT02979899).

$70888 \quad$ (https://ClinicalTrials.gov/show/NCT01806064).

$70989 \quad$ (https://ClinicalTrials.gov/show/NCT00582985).

$71090 \quad$ (https://ClinicalTrials.gov/show/NCT03418324).

$71191 \quad$ (https://ClinicalTrials.gov/show/NCT03181308).

$71292 \quad$ (https://ClinicalTrials.gov/show/NCT01727089).

$71393 \quad$ (https://ClinicalTrials.gov/show/NCT01381861).

$71494 \quad$ (https://ClinicalTrials.gov/show/NCT01090765).

$71595 \quad$ (https://ClinicalTrials.gov/show/NCT02354612).

$71696 \quad$ (https://ClinicalTrials.gov/show/NCT01564914).

$71797 \quad$ (https://ClinicalTrials.gov/show/NCT01648348).

$71898 \quad$ Schoonderwoerd, M. J. et al. Targeting endoglin expressing regulatory T cells in the 719 tumor microenvironment enhances the effect of PD1 checkpoint inhibitor

720 immunotherapy. Clin Cancer Res, doi:10.1158/1078-0432.CCR-19-2889 (2020).

72199 Bandyopadhyay, A. et al. Systemic administration of a soluble betaglycan suppresses

722 tumor growth, angiogenesis, and matrix metalloproteinase-9 expression in a human 723 xenograft model of prostate cancer. Prostate 63, 81-90, doi:10.1002/pros.20166 (2005).

724100 Dong, M. et al. The type III TGF-beta receptor suppresses breast cancer progression. $J$ $725 \quad$ Clin Invest 117, 206-217, doi:10.1172/JCI29293 (2007).

726101 Naumann, U. et al. Glioma gene therapy with soluble transforming growth factor-beta 727 receptors II and III. Int J Oncol 33, 759-765 (2008).

728102 Finger, E. C. et al. TbetaRIII suppresses non-small cell lung cancer invasiveness and 729 tumorigenicity. Carcinogenesis 29, 528-535, doi:10.1093/carcin/bgm289 (2008). 
730103 Bandyopadhyay, A. et al. Antitumor activity of a recombinant soluble betaglycan in human breast cancer xenograft. Cancer Res 62, 4690-4695 (2002).

104 Lee, J. D., Hempel, N., Lee, N. Y. \& Blobe, G. C. The type III TGF-beta receptor suppresses breast cancer progression through GIPC-mediated inhibition of TGF-beta

105 Gallo-Oller, G. et al. P144, a Transforming Growth Factor beta inhibitor peptide, generates antitumoral effects and modifies SMAD7 and SKI levels in human

106 Llopiz, D. et al. Peptide inhibitors of transforming growth factor-beta enhance the efficacy of antitumor immunotherapy. Int J Cancer 125, 2614-2623,

107 Gao, J. et al. Integrative analysis of complex cancer genomics and clinical profiles using the cBioPortal. Sci Signal 6, pl1, doi:10.1126/scisignal.2004088 (2013).

109 Nagy, Á., Lánczky, A., Menyhárt, O. \& Győrffy, B. Validation of miRNA prognostic power in hepatocellular carcinoma using expression data of independent datasets. Sci Rep

110 Fekete, J. T. \& Gyorffy, B. ROCplot.org: Validating predictive biomarkers of chemotherapy/hormonal therapy/anti-HER2 therapy using transcriptomic data of 3,104 breast cancer patients. Int J Cancer 145, 3140-3151, doi:10.1002/ijc.32369 (2019).

112 Huang da, W., Sherman, B. T. \& Lempicki, R. A. Systematic and integrative analysis of large gene lists using DAVID bioinformatics resources. Nat Protoc 4, 44-57,

757113 Broad, D. DepMap 20Q1 Public. (2020).

114 Katayama, Y. et al. Clinical Significance of. In Vivo 31, 565-571, doi:10.21873/invivo.11095 (2017). 
116 Kita, A. et al. Activin B Regulates Adhesion, Invasiveness, and Migratory Activities in Oral Cancer: a Potential Biomarker for Metastasis. J Cancer 8, 2033-2041, doi:10.7150/jca.18714 (2017).

117 Chen, Z. L., Qin, L., Peng, X. B., Hu, Y. \& Liu, B. INHBA gene silencing inhibits gastric cancer cell migration and invasion by impeding activation of the TGF- $\beta$ signaling pathway. J Cell Physiol 234, 18065-18074, doi:10.1002/jcp.28439 (2019).

118 Li, Y. et al. Betaglycan (TGFBR3) Functions as an Inhibin A, but Not Inhibin B, Coreceptor in Pituitary Gonadotrope Cells in Mice. Endocrinology 159, 4077-4091, doi:10.1210/en.2018-00770 (2018).

119 Makanji, Y., Harrison, C. A., Stanton, P. G., Krishna, R. \& Robertson, D. M. Inhibin A and $\mathrm{B}$ in vitro bioactivities are modified by their degree of glycosylation and their affinities to betaglycan. Endocrinology 148, 2309-2316, doi:10.1210/en.2006-1612 (2007).

120 Makanji, Y. et al. Suppression of inhibin A biological activity by alterations in the binding site for betaglycan. J Biol Chem 283, 16743-16751, doi:10.1074/jbc.M801045200 (2008).

121 Wiater, E. et al. Endogenous betaglycan is essential for high-potency inhibin antagonism in gonadotropes. Mol Endocrinol 23, 1033-1042, doi:10.1210/me.2009-0021 (2009).

122 Meyers, R. M. et al. Computational correction of copy number effect improves specificity of CRISPR-Cas9 essentiality screens in cancer cells. Nat Genet 49, 17791784, doi:10.1038/ng.3984 (2017).

123 Dempster, J. M. et al. Extracting Biological Insights from the Project Achilles GenomeScale CRISPR Screens in Cancer Cell Lines. bioRxiv, 720243, doi:10.1101/720243 (2019).

124 Ghandi, M. et al. Next-generation characterization of the Cancer Cell Line Encyclopedia. Nature 569, 503-508, doi:10.1038/s41586-019-1186-3 (2019).

125 Tsherniak, A. et al. Defining a Cancer Dependency Map. Cell 170, 564-576.e516, doi:10.1016/j.cell.2017.06.010 (2017).

126 Nishida, J., Miyazono, K. \& Ehata, S. Decreased TGFBR3/betaglycan expression enhances the metastatic abilities of renal cell carcinoma cells through TGF- $\beta$-dependent and -independent mechanisms. Oncogene 37, 2197-2212, doi:10.1038/s41388-017-00840 (2018).

127 Frias, A. E., Li, H., Keeney, G. L., Podratz, K. C. \& Woodruff, T. K. Preoperative serum level of inhibin A is an independent prognostic factor for the survival of postmenopausal women with epithelial ovarian carcinoma. Cancer 85, 465-471, doi:10.1002/(sici)10970142(19990115)85:2<465::aid-cncr26>3.0.co;2-w (1999). 
128 Bashir, M., Damineni, S., Mukherjee, G. \& Kondaiah, P. Activin-A signaling promotes epithelial-mesenchymal transition, invasion, and metastatic growth of breast cancer. NPJ Breast Cancer 1, 15007, doi:10.1038/npjbcancer.2015.7 (2015).

129 Okano, M. et al. Significance of INHBA expression in human colorectal cancer. Oncol Rep 30, 2903-2908, doi:10.3892/or.2013.2761 (2013).

130 Abrahao-Machado, L. F. \& Scapulatempo-Neto, C. HER2 testing in gastric cancer: An

131 Kim, S. K. et al. Structural Adaptation in Its Orphan Domain Engenders Betaglycan with an Alternate Mode of Growth Factor Binding Relative to Endoglin. Structure 27, 1427 1442.e1424, doi:10.1016/j.str.2019.06.010 (2019).

132 Chang, H. Y. et al. Robustness, scalability, and integration of a wound-response gene expression signature in predicting breast cancer survival. Proc Natl Acad Sci U S A 102, 3738-3743, doi:10.1073/pnas.0409462102 (2005).

812133 Haider, S. et al. A multi-gene signature predicts outcome in patients with pancreatic ductal adenocarcinoma. Genome Med 6, 105, doi:10.1186/s13073-014-0105-3 (2014).

Hallett, R. M., Dvorkin-Gheva, A., Bane, A. \& Hassell, J. A. A gene signature for predicting outcome in patients with basal-like breast cancer. Sci Rep 2, 227, doi:10.1038/srep00227 (2012).

817135 Kim, S. Y. \& Kim, Y. S. A gene sets approach for identifying prognostic gene signatures

136 Kanehisa, M. \& Goto, S. KEGG: kyoto encyclopedia of genes and genomes. Nucleic Acids Res 28, 27-30, doi:10.1093/nar/28.1.27 (2000). (2008).

139 Das, S. \& Marsden, P. A. Angiogenesis in glioblastoma. N Engl J Med 369, 1561-1563, doi:10.1056/NEJMcibr1309402 (2013).

140 Longui, C. A. et al. Inhibin alpha-subunit (INHA) gene and locus changes in paediatric adrenocortical tumours from TP53 R337H mutation heterozygote carriers. J Med Genet 41, 354-359, doi:10.1136/jmg.2004.018978 (2004). 
832141 Tremblay, J. J. \& Viger, R. S. GATA factors differentially activate multiple gonadal

833

834

835

836

837

838

839

840

841

842

843

844

845

846

847

848

849

850

851

852

853

854

855

856

857

858

859

860

861

862

863

864

865

866 promoters through conserved GATA regulatory elements. Endocrinology 142, 977-986, doi:10.1210/endo.142.3.7995 (2001).

142 Gong, Y. et al. GATA4 inhibits cell differentiation and proliferation in pancreatic cancer. PLoS One 13, e0202449, doi:10.1371/journal.pone.0202449 (2018).

143 Han, Q. et al. GATA4 is highly expressed in childhood acute lymphoblastic leukemia, promotes cell proliferation and inhibits apoptosis by activating BCL2 and MDM2. Mol Med Rep 16, 6290-6298, doi:10.3892/mmr.2017.7369 (2017).

144 Nikiteas, N. I. et al. Vascular endothelial growth factor and endoglin (CD-105) in gastric cancer. Gastric Cancer 10, 12-17, doi:10.1007/s10120-006-0401-8 (2007).

145 Chen, C.-Y. \& Sheu, M.-J. Endoglin targeting inhibits tumor angiogenesis in non-small cell lung cancer. The FASEB Journal 32, 695.616-695.616, doi:10.1096/fasebj.2018.32.1_supplement.695.16 (2018).

146 Henry, L. A. et al. Endoglin expression in breast tumor cells suppresses invasion and metastasis and correlates with improved clinical outcome. Oncogene 30, 1046-1058, doi:10.1038/onc.2010.488 (2011).

147 Kauer, J. et al. CD105 (Endoglin) as negative prognostic factor in AML. Sci Rep 9 , 18337, doi:10.1038/s41598-019-54767-x (2019).

148 Bhola, N. E. et al. TGF- $\beta$ inhibition enhances chemotherapy action against triplenegative breast cancer. J Clin Invest 123, 1348-1358, doi:10.1172/JCI65416 (2013).

149 Vogiatzi, F. et al. Mutant 553 promotes tumor progression and metastasis by the endoplasmic reticulum UDPase ENTPD5. Proc Natl Acad Sci U S A 113, E8433-E8442, doi:10.1073/pnas.1612711114 (2016).

150 Moyano-Galceran, L. et al. Adaptive RSK-EphA2-GPRC5A signaling switch triggers chemotherapy resistance in ovarian cancer. EMBO Mol Med 12, e11177, doi:10.15252/emmm.201911177 (2020).

151 De Robertis, M. et al. Dysregulation of EGFR Pathway in EphA2 Cell Subpopulation Significantly Associates with Poor Prognosis in Colorectal Cancer. Clin Cancer Res 23, 159-170, doi:10.1158/1078-0432.CCR-16-0709 (2017).

152 Zhuang, G. et al. Elevation of receptor tyrosine kinase EphA2 mediates resistance to trastuzumab therapy. Cancer Res 70, 299-308, doi:10.1158/0008-5472.CAN-09-1845 (2010).

153 Huang, J. et al. EphA2 promotes epithelial-mesenchymal transition through the Wnt/Bcatenin pathway in gastric cancer cells. Oncogene 33, 2737-2747, doi:10.1038/onc.2013.238 (2014). 
154 Kim, C. Y., Oh, J. H., Lee, J. Y. \& Kim, M. H. The LncRNA HOTAIRM1 Promotes Tamoxifen Resistance by Mediating HOXA1 Expression in ER+ Breast Cancer Cells. $J$ Cancer 11, 3416-3423, doi:10.7150/jca.38728 (2020).

155 Bitu, C. C. et al. HOXA1 is overexpressed in oral squamous cell carcinomas and its expression is correlated with poor prognosis. BMC Cancer 12, 146, doi:10.1186/14712407-12-146 (2012).

156 Wardwell-Ozgo, J. et al. HOXA1 drives melanoma tumor growth and metastasis and elicits an invasion gene expression signature that prognosticates clinical outcome. Oncogene 33, 1017-1026, doi:10.1038/onc.2013.30 (2014).

157 Zimmer, B. M. et al. Loss of exogenous androgen dependence by prostate tumor cells is associated with elevated glucuronidation potential. Horm Cancer 7, 260-271, doi:10.1007/s12672-016-0268-z (2016).

158 Allain, E. P., Rouleau, M., Lévesque, E. \& Guillemette, C. Emerging roles for UDPglucuronosyltransferases in drug resistance and cancer progression. Br J Cancer 122, 1277-1287, doi:10.1038/s41416-019-0722-0 (2020).

159 Gummow, B. M., Winnay, J. N. \& Hammer, G. D. Convergence of Wnt signaling and steroidogenic factor-1 (SF-1) on transcription of the rat inhibin alpha gene. J Biol Chem 278, 26572-26579, doi:10.1074/jbc.M212677200 (2003).

160 de la Fuente-Granada, M., Olguín-Alor, R., Ortega-Francisco, S., Bonifaz, L. C. \& Soldevila, G. Inhibins regulate peripheral regulatory $\mathrm{T}$ cell induction through modulation of dendritic cell function. FEBS Open Bio 9, 137-147, doi:10.1002/2211-5463.12555 (2019).

161 Li, J. et al. A 5-Gene Signature Is Closely Related to Tumor Immune Microenvironment and Predicts the Prognosis of Patients with Non-Small Cell Lung Cancer. Biomed Res Int 2020, 2147397, doi:10.1155/2020/2147397 (2020).

162 Ruiz, E. M. L. et al. A novel gene panel for prediction of lymph-node metastasis and recurrence in patients with thyroid cancer. Surgery 167, 73-79, doi:10.1016/j.surg.2019.06.058 (2020).

163 Yang, H. et al. From big data to diagnosis and prognosis: gene expression signatures in liver hepatocellular carcinoma. PeerJ 5, e3089, doi:10.7717/peerj.3089 (2017).

164 Huang, L. et al. Identification of a 7-gene signature that predicts relapse and survival for early stage patients with cervical carcinoma. Med Oncol 29, 2911-2918, doi:10.1007/s12032-012-0166-3 (2012).

165 Torsney, E., Charlton, R., Parums, D., Collis, M. \& Arthur, H. M. Inducible expression of human endoglin during inflammation and wound healing in vivo. Inflamm Res 51, 464470, doi:10.1007/p100012413 (2002). 
903166 Alzahrani, A. et al. Endoglin haploinsufficiency is associated with differential regulation 904 of extracellular matrix production during skin fibrosis and cartilage repair in mice. $J$ Cell 905 Commun Signal 12, 379-388, doi:10.1007/s12079-018-0461-7 (2018).

906167 Mythreye, K., Knelson, E. H., Gatza, C. E., Gatza, M. L. \& Blobe, G. C. T $\beta$ RIII/ $\beta$ -

907 arrestin2 regulates integrin $\alpha 5 \beta 1$ trafficking, function, and localization in epithelial cells.

909168 Jarosz, M. et al. Therapeutic antitumor potential of endoglin-based DNA vaccine $910 \quad$ combined with immunomodulatory agents. Gene Ther 20, 262-273, 911 doi:10.1038/gt.2012.28 (2013).

912 


\section{FIGURES}

915

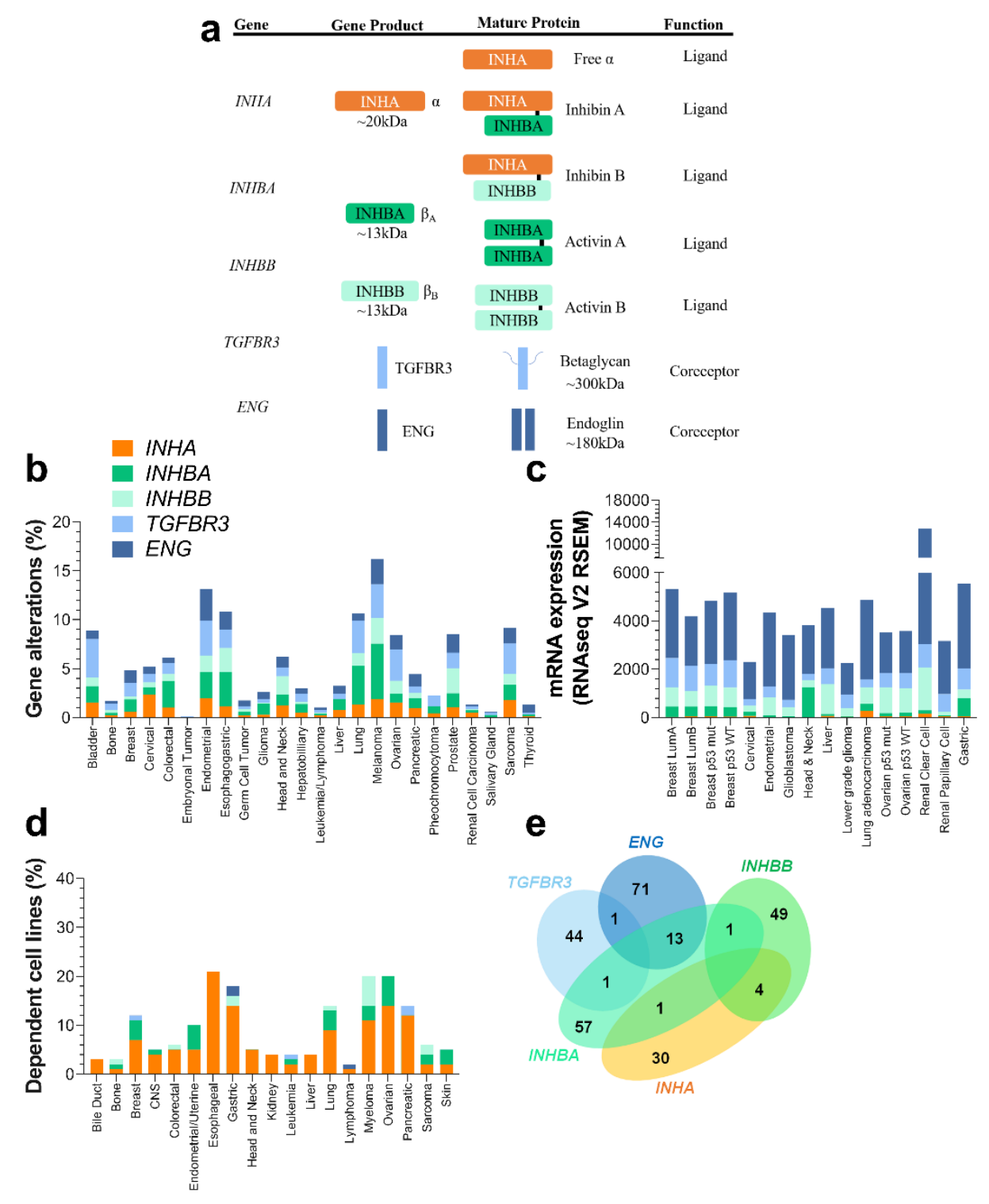

Figure 1. Expression and gene alterations of inhibin and activins. (a) Genes encoding INHA, INHBA, and INHBA produce monomeric $\alpha$ and $\beta$ subunits. These subunits combine to form either homo or heterodimers representing mature inhibin $\mathrm{A}$, inhibin $\mathrm{B}$, activin $\mathrm{A}$, and activin $\mathrm{B}$. (b) TCGA base analysis of gene alteration frequencies of INHA, INHBA, INHBB, TGBFR3, and ENG. (c) Analysis of gene expression levels, also from TCGA sets, of the same genes as in (b) in a subset of cancer types and subtypes. Analysis included 16 studies and 6258 samples. (d) DepMap analysis of cell line dependency from indicated cancer types on each of the genes in (b). (e) Venn diagram illustrating the number of common dependent genes for each gene in (b). All numeric data are available in Supplementary Table 1. Abbreviations - CNS: Central Nervous System; LumA: Luminal A; LumB: Luminal B; mut: mutated; WT: wild-type. 
a

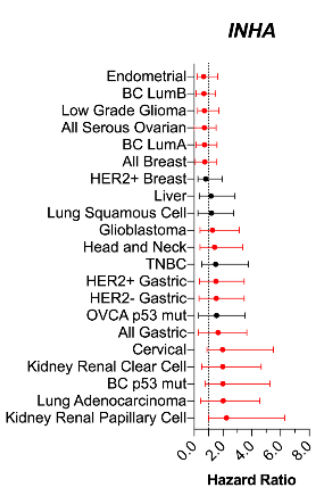

b

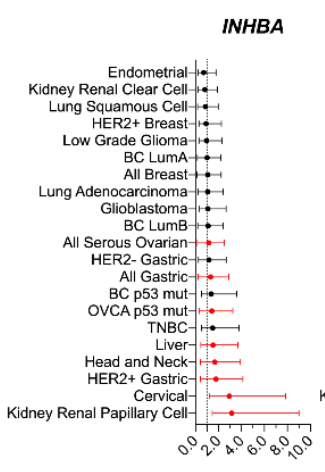

C

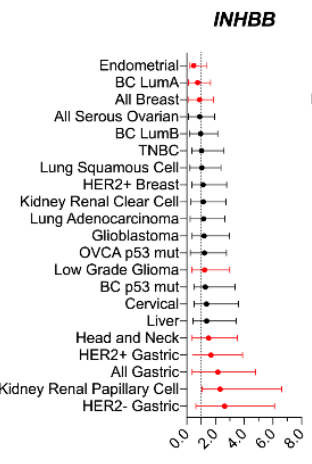

d

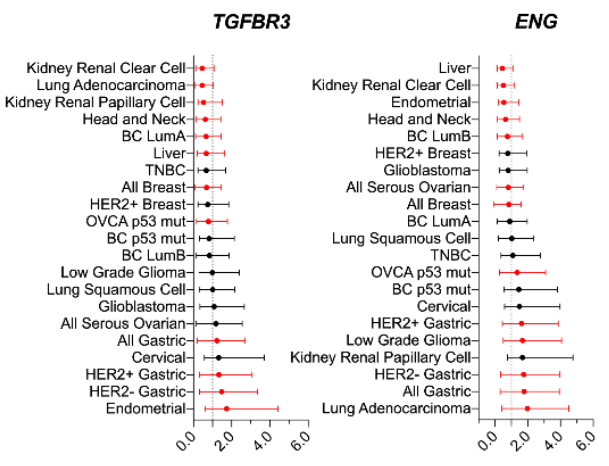

Figure 2. Impact of INHA, INHBA, INHBB, TGFBR3, and ENG on patient survival in

928 indicated cancers. (a) Forest Plot with Hazard Ratios (HR) of indicated genes generated from KM 929 Plotter or data from cBioportal. Black dots represent HR that are not statistically significant ( $p>$ $930 \quad 0.05)$ and red dots represent HR that are statistically significant $(p<0.05)$. All numeric data are 931 available in Supplementary Table 2. 
a
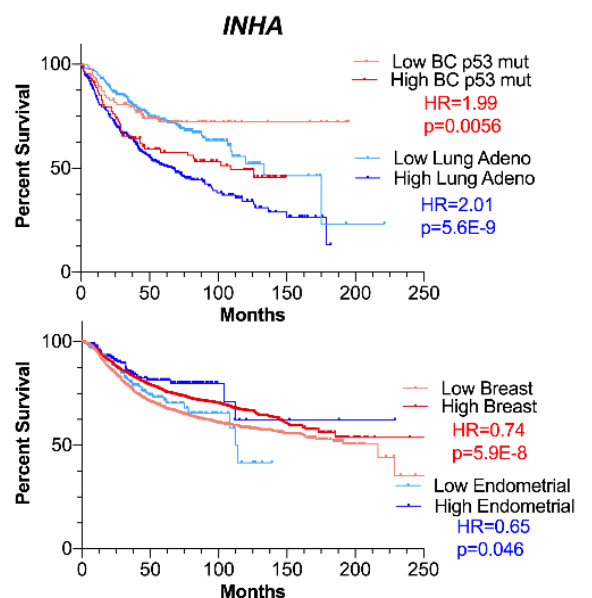

b
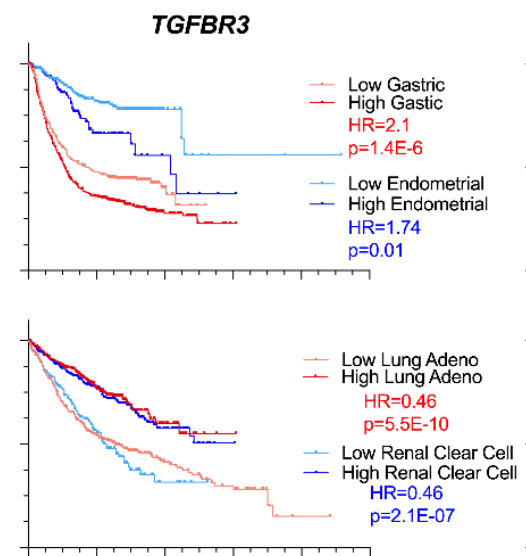

C
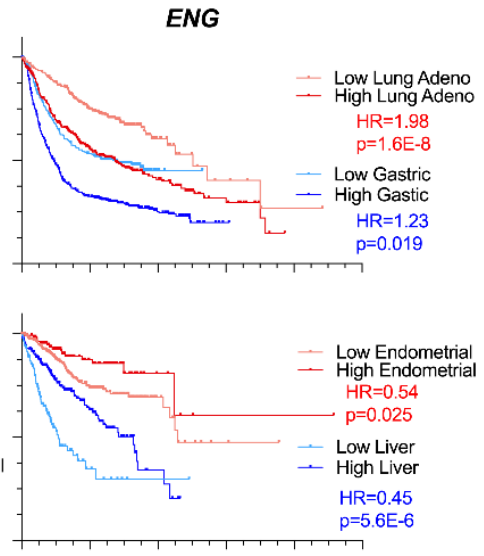

932

933

934

935

936

937

938
Figure 3. Representative Kaplan Meier curves for INHA, TGFBR3, and ENG. Event-free survival in indicated cancers using median to separate expression (lighter shade indicates bottom patients expressing bottom 50\% and darker shade top 50\%). Survival curves represent OS for all cancers except breast cancer (RFS) and ovarian cancer (PFS). Top plots show cancer types where the gene is a negative predictor of survival, and bottom plots show cancer types where the gene is a negative predictor. 

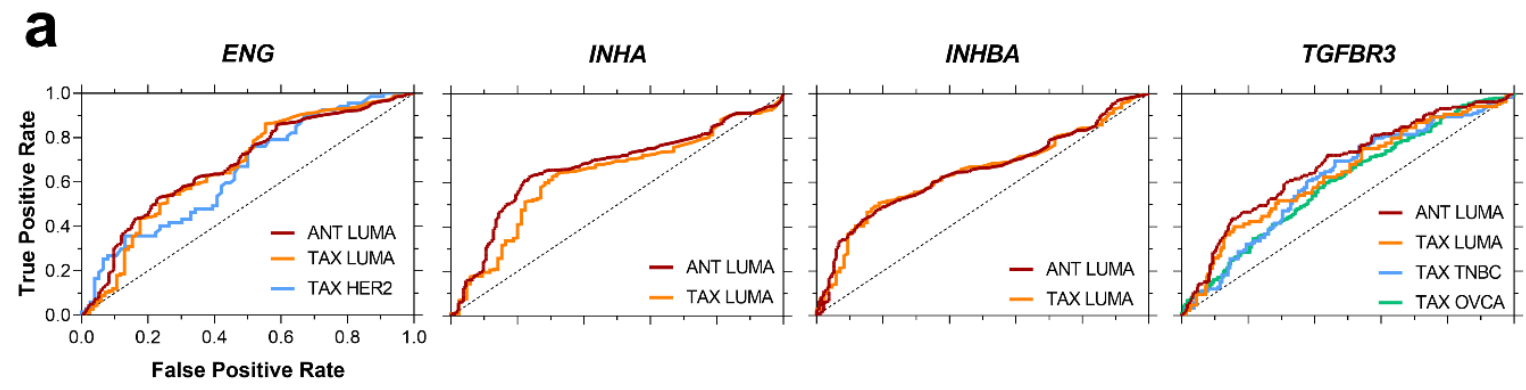

\section{b}

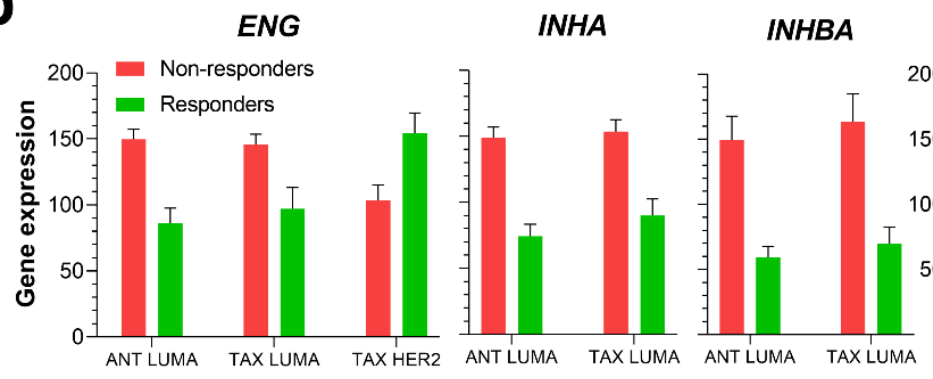

INHA

TGFBR3

Figure 4. ROC plots (a) and gene expression (b) of indicated genes for different chemotherapy regimens. (a) ROC curves, in which performance ability was verified (i.e., AUC > 0.6), were plotted for $E N G, I N H A, I N H B A$, and TGFBR3. (b) Gene expression for each investigated gene between responders and non-responders for the assessed pharmacological treatments. Abbreviations: ANT: anthracycline; TAX: taxane; LUMA: luminal A; TNBC: triplenegative breast cancer; OVCA: serous ovarian cancer. 


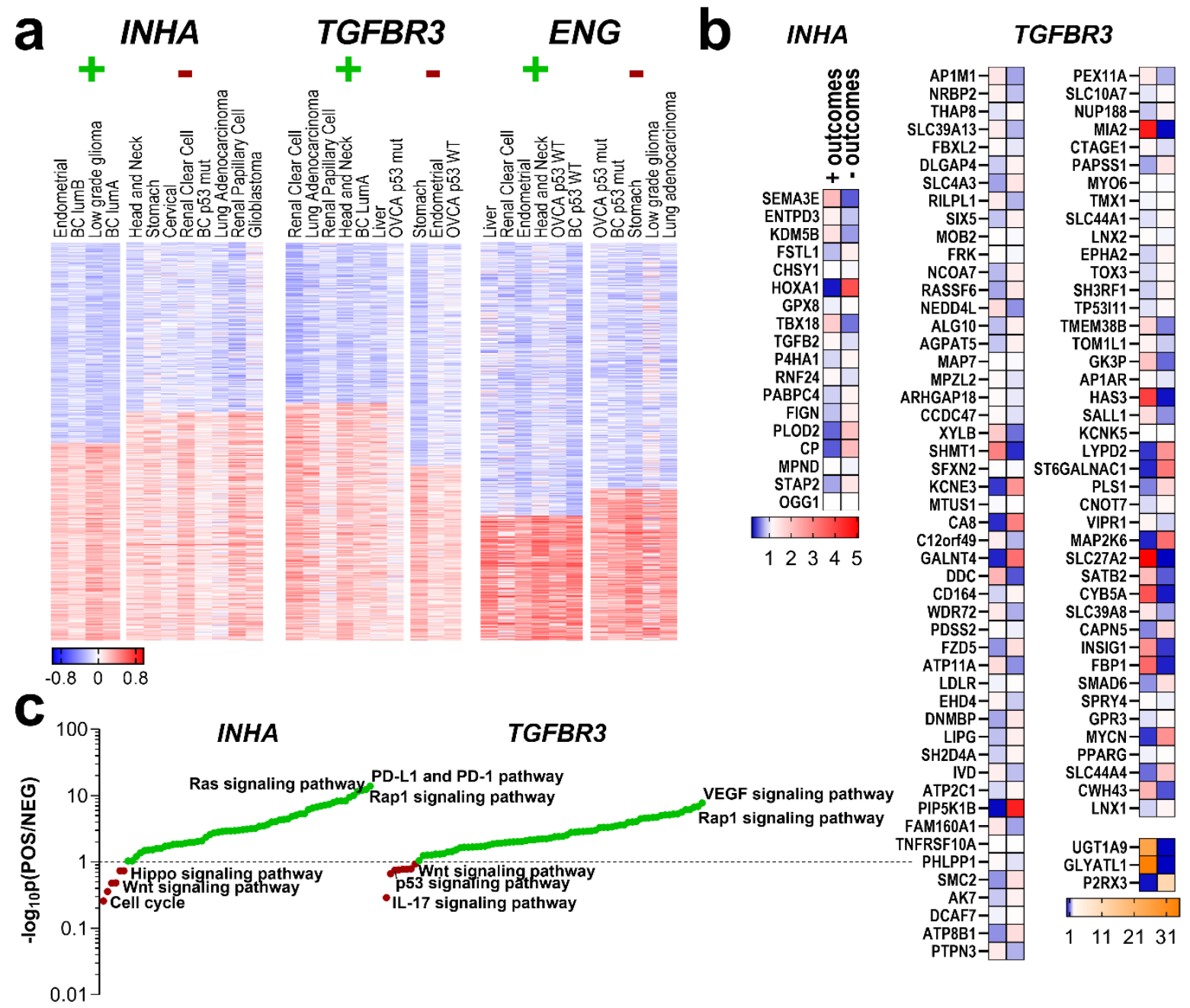

946
Figure 5. Gene signatures and expression patterns for cancers where INHA, TGFBR3, or ENG predicted survival outcomes. (a) Cancer types in which either INHA TGFBR3 or ENG had either positive $(+)$ or negative (-) survival outcomes had their RNA-seq gene data correlation clustered for either low or high degree of correlations to each INHA, TGFBR3 or ENG as indicated. (b) mRNA abundance of a subset of common genes obtained from pairwise comparisons of the top correlated genes from the positive outcome with the genes that had lower correlations in the negative outcome set, and vice-versa. mRNA expression was assessed in each cancer set.* $\mathrm{p}<$ $0.05 * * \mathrm{p}<0.01 * * * \mathrm{p}<0.001 * * * * \mathrm{p}<0.0001$ (c) Pathway analysis after BioGRID assessment of the significant genes from (b), ranked with a ratio of significance between sets from the positive and negative outcomes for each gene. 


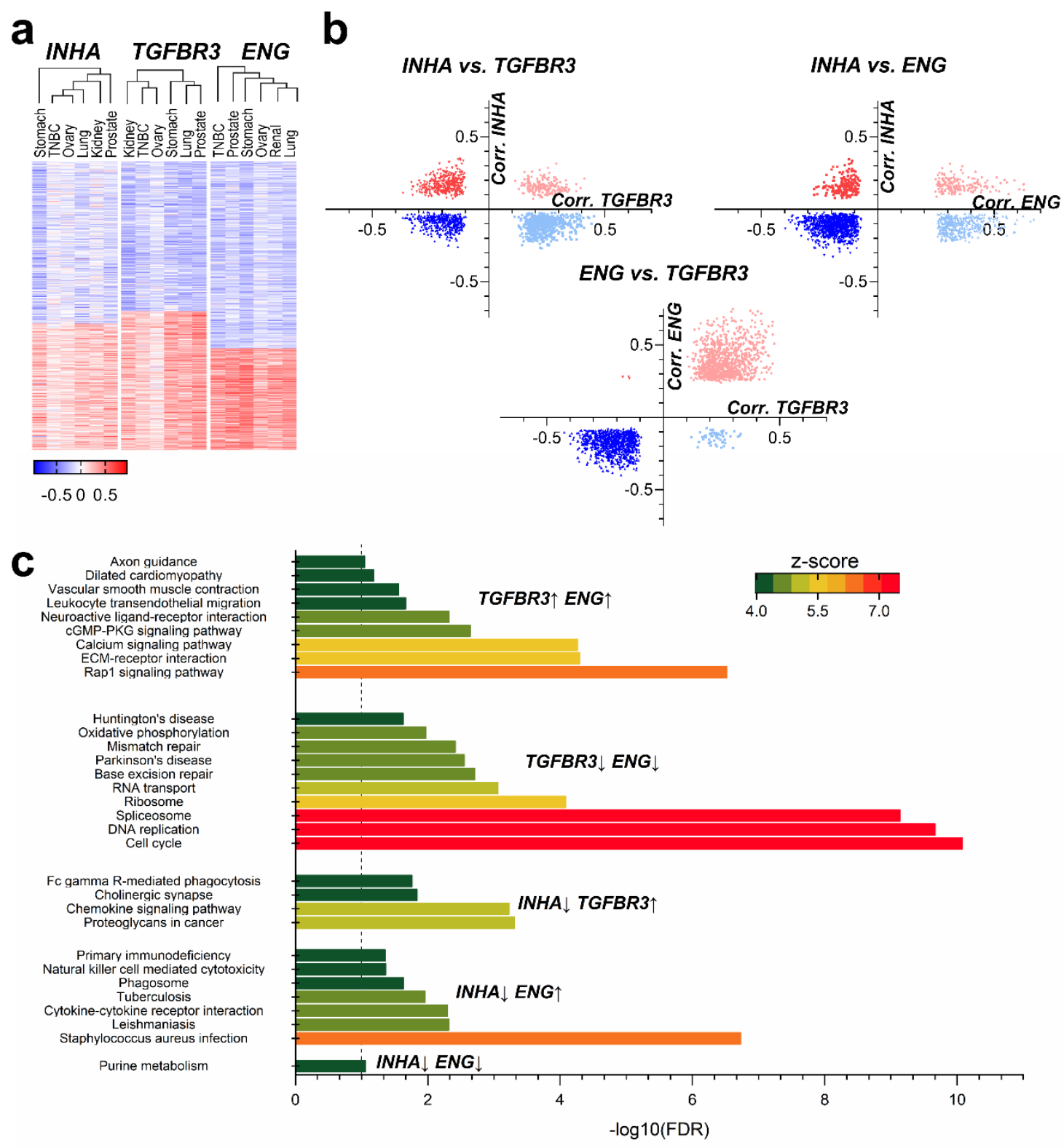
Common genes that were found in each group of correlated genes (e.g., negative correlation to $I N H A$ vs. positive to TGFBR3 and all combinations) is presented. (c) KEGG pathway analysis for groups of genes correlated with the indicated combination. Unique pathways with an FDR below 0.05 were identified for the comparisons and are presented. 
bioRxiv preprint doi: https://doi.org/10.1101/2020.06.25.171942; this version posted June 27,2020 . The copyright holder for this preprint (which was not certified by peer review) is the author/funder, who has granted bioRxiv a license to display the preprint in perpetuity. It is made available under aCC-BY-NC-ND 4.0 International license.

\section{TABLES}

966

967

968

969

970

Table 1. p values and Hazard Ratios (HR) from survival curves assessing the relationship between TGFBR3/ENG and INHA on patient survival. Survival curves were generated in KM Plotter for all cancer types. Survival curves represent overall survival, progression free survival (marked with *), or relapse free survival (marked with ${ }^{\#}$ ) for patients expressing high or low mRNA (split by median) of the indicated gene.

\begin{tabular}{|c|c|c|c|c|c|c|c|}
\hline Type & Subtype & Variable & $I N H A$ & $T G F B R 3$ & $\begin{array}{l}\text { INHA and } \\
T G F B R 3\end{array}$ & $\begin{array}{l}\text { INHA in } \\
\text { High } \\
\text { TGFBR3 } \\
\text { Patients } \\
\end{array}$ & $\begin{array}{l}\text { INHA in Low } \\
\text { TGFBR3 } \\
\text { Patients }\end{array}$ \\
\hline \multirow{4}{*}{ Breast $^{\#}$} & \multirow[b]{2}{*}{ All } & $\mathrm{p}$ value & $5.9 \mathrm{E}-8$ & $4 \mathrm{E}-11$ & $4.5 \mathrm{E}-12$ & .00026 & $5.9 \mathrm{E}-6$ \\
\hline & & $\begin{array}{l}\text { Hazard Ratio } \\
(\mathrm{HR})\end{array}$ & .74 & .69 & .68 & .74 & .74 \\
\hline & \multirow[b]{2}{*}{ p53 Mutated } & $\mathrm{p}$ value & .0056 & .41 & .82 & .27 & .015 \\
\hline & & $\begin{array}{l}\text { Hazard Ratio } \\
(\mathrm{HR})\end{array}$ & 1.99 & .82 & .95 & 1.5 & 2.29 \\
\hline \multirow{4}{*}{ Ovarian* } & \multirow[b]{2}{*}{ All } & $\mathrm{p}$ value & $1.5 \mathrm{E}-6$ & .047 & .16 & .096 & .0032 \\
\hline & & $\begin{array}{l}\text { Hazard Ratio } \\
(\mathrm{HR})\end{array}$ & .71 & 1.16 & .9 & 1.18 & .82 \\
\hline & \multirow[b]{2}{*}{ p53 Mutated } & \multirow{2}{*}{$\begin{array}{l}\mathrm{p} \text { value } \\
\text { Hazard Ratio } \\
(\mathrm{HR})\end{array}$} & .00039 & .039 & .1 & .021 & .00075 \\
\hline & & & 1.55 & .79 & .83 & 1.51 & 1.74 \\
\hline \multirow{4}{*}{ Lung } & \multirow[b]{2}{*}{ All } & \multirow{2}{*}{$\begin{array}{l}\mathrm{p} \text { value } \\
\text { Hazard Ratio } \\
(\mathrm{HR})\end{array}$} & .00029 & $3.4 \mathrm{E}-7$ & $1.4 \mathrm{E}-6$ & $4.4 \mathrm{E}-5$ & .18 \\
\hline & & & 1.26 & .65 & .73 & 1.49 & 1.12 \\
\hline & \multirow[b]{2}{*}{ Adenocarcinoma } & \multirow{2}{*}{$\begin{array}{l}\mathrm{p} \text { value } \\
\text { Hazard Ratio } \\
(\mathrm{HR})\end{array}$} & $5.6 \mathrm{E}-9$ & $5.5 \mathrm{E}-10$ & $3.1 \mathrm{E}-7$ & $1.7 \mathrm{E}-5$ & $1.6 \mathrm{E}-8$ \\
\hline & & & 2.01 & .46 & .53 & 2.49 & 1.98 \\
\hline \multirow[b]{2}{*}{ Kidney } & \multirow[b]{2}{*}{ Renal Clear Cell } & \multirow{2}{*}{$\begin{array}{l}\text { p value } \\
\text { Hazard Ratio } \\
(\mathrm{HR})\end{array}$} & $7.1 \mathrm{E}-06$ & $2.1 \mathrm{E}-7$ & $3.3 \mathrm{E}-05$ & .2 & $9.0 \mathrm{E}-06$ \\
\hline & & & 1.98 & .46 & .53 & 1.42 & 2.75 \\
\hline Type & Subtype & Variable & $I N H A$ & $E N G$ & $\begin{array}{l}I N H A \\
E N G\end{array}$ & $\begin{array}{l}\text { INHA in } \\
\text { High ENG } \\
\text { Patients }\end{array}$ & $\begin{array}{l}\text { INHA in Low } \\
\text { ENG Patients }\end{array}$ \\
\hline \multirow{4}{*}{ Breast $^{\#}$} & \multirow[b]{2}{*}{ All } & \multirow{2}{*}{$\begin{array}{l}\text { p value } \\
\text { Hazard Ratio } \\
(\mathrm{HR})\end{array}$} & $5.9 \mathrm{E}-8$ & .0014 & $7.4 \mathrm{E}-6$ & .0043 & .0027 \\
\hline & & & .74 & .84 & .78 & .79 & .79 \\
\hline & \multirow[b]{2}{*}{ p53 Mutated } & \multirow{2}{*}{$\begin{array}{l}\text { p value } \\
\text { Hazard Ratio } \\
(\mathrm{HR})\end{array}$} & .0056 & .12 & .057 & .26 & .035 \\
\hline & & & 1.99 & 1.46 & 1.6 & .69 & 2.24 \\
\hline \multirow{4}{*}{ Ovarian* } & \multirow[b]{2}{*}{ All } & \multirow{2}{*}{$\begin{array}{l}\mathrm{p} \text { value } \\
\text { Hazard Ratio } \\
(\mathrm{HR})\end{array}$} & $1.5 \mathrm{E}-6$ & .0032 & .00011 & .00016 & .065 \\
\hline & & & .71 & .82 & .77 & .71 & .83 \\
\hline & \multirow[b]{2}{*}{ p53 Mutated } & \multirow{2}{*}{$\begin{array}{l}\text { p value } \\
\text { Hazard Ratio } \\
(\mathrm{HR})\end{array}$} & .00039 & .0098 & .00091 & $1.8 \mathrm{E}-6$ & .18 \\
\hline & & & 1.55 & 1.36 & 1.49 & 2.12 & .8 \\
\hline \multirow{4}{*}{ Lung } & \multirow[b]{2}{*}{ All } & \multirow{2}{*}{$\begin{array}{l}\text { p value } \\
\text { Hazard Ratio } \\
(\mathrm{HR})\end{array}$} & .00029 & .0056 & .063 & .47 & $5.8 \mathrm{E}-8$ \\
\hline & & & 1.26 & 1.2 & 1.13 & 1.07 & 1.66 \\
\hline & \multirow[b]{2}{*}{ Adenocarcinoma } & \multirow{2}{*}{$\begin{array}{l}\text { p value } \\
\text { Hazard Ratio } \\
(\mathrm{HR})\end{array}$} & $5.6 \mathrm{E}-9$ & $1.6 \mathrm{E}-8$ & $5.6 \mathrm{E}-12$ & .14 & .00041 \\
\hline & & & 2.01 & 1.98 & 2.3 & 1.25 & 2.12 \\
\hline & & $\mathrm{p}$ value & $7.1 \mathrm{E}-06$ & $8.6 \mathrm{E}-6$ & $4.5 \mathrm{E}-05$ & .072 & $2.5 \mathrm{E}-06$ \\
\hline Kidney & Renal Clear Cell & $\begin{array}{l}\text { Hazard Ratio } \\
(\mathrm{HR})\end{array}$ & 1.98 & .51 & .53 & 1.53 & 2.6 \\
\hline
\end{tabular}


972 Table 2. Prognostic performance of each delineated probit model. For either an INHA or TGFBR3 model, the described cancer

973 types and subtypes used to analyze the positive $(+)$, and negative $(-)$ outcomes are shown. The number of genes in each model, the 974 model's specificity (i.e., how the model certifies true positives), sensitivity (i.e., how the model certifies true negatives), and their

975 false positive and false negative ratios are shown. The correct classification ratio is also highlighted below.

INHA model

- Endometrial;

Cancer types (+)

Cancer types (-)

- Renal Clear Cell;
- BC lum A;

- BC lum B;

- Low grade glioma

- Head and Neck;

- Stomach;

- Cervical;

- BC p53 mut;

- Lung adenocarcinoma;

- Renal Papillary Cell;

- Glioblastoma.

\begin{tabular}{ccc} 
& $\begin{array}{l}\bullet \\
\end{array}$ & \\
& - BC 553 mut; & \\
& - Renal Papillary Cell; & \\
& Glioblastoma. & \\
\hline Genes in model & 43 & 37 \\
\hline Specificity & $90.76 \%$ & $98.42 \%$ \\
\hline Sensitivity & $93.17 \%$ & $91.56 \%$ \\
\hline False positives ratio & $6.83 \%$ & $8.44 \%$ \\
\hline False negative ratio & $9.24 \%$ & $1.58 \%$ \\
\hline Accuracy & $\mathbf{9 2 . 2 5 \%}$ & $\mathbf{9 6 . 7 0 \%}$ \\
\hline
\end{tabular}

- Renal Clear Cell;

- Lung adenocarcinoma;

- Renal Papillary Cell;

- Head and Neck;

- BC lum A;

- Liver;

- OVCA p53 mut

- Stomach;

- Endometrial;

- OVCA p53 WT. 